unesp $^{\text {sit }}$

UNIVERSIDADE ESTADUAL PAULISTA

FACULDADE DE ODONTOLOGIA DE ARARAQUARA

Cármen Regina Coldebella

\title{
Efeito da aplicação de ondas de ultrassom sobre cimentos de ionômero de vidro e dentina subjacente
}

\begin{abstract}
Tese apresentada ao Programa de PósGraduação em Ciências Odontológicas - Área de concentração em Odontopediatria, da Faculdade de Odontologia de Araraquara, da Universidade Estadual Paulista "Júlio Mesquita Filho", para obtenção do Título de Doutor em Odontopediatria.
\end{abstract}


Coldebella, Carmen Regina

Efeito da aplicação de ondas de ultra-som sobre cimentos de ionômero de vidro e dentina subjacente / Carmen Regina Coldebella.Araraquara: [s.n.], 2010.

$111 \mathrm{f} . ; 30 \mathrm{~cm}$.

Tese (Doutorado) - Universidade Estadual Paulista, Faculdade de Odontologia

Orientadora : Profa. Dra. Ângela Cristina Cilense Zuanon

1. Cimentos de ionômeros de vidro 2. Ultrassom 3. Dureza 4. Resistência ao cisalhamento 5. Desgaste de restauração dentária 6. Escovação dentária 7. Dentina 8. Cárie dentária I. Título

Ficha catalográfica elaborada pela Bibliotecária Marley C. Chiusoli Montagnoli, CRB-8/5646 Serviço Técnico de Biblioteca e Documentação da Faculdade de Odontologia de Araraquara / UNESP 


\title{
CARMEN REGINA COLDEBELLA
}

\section{Efeito da aplicação de ondas de ultrassom sobre cimentos de ionômero de vidro e dentina subjacente}

\author{
COMISSÃO JULGADORA \\ Tese para obtenção do Título de Doutor
}

Presidente e Orientador: Profa. Dra. Angela Cristina Cilense Zuânon

Examinador: Profa. Dra. Mariane Emi Sanabe

Examinador: Prof. Dr. Paulo Zárate Pereira

Examinador: Profa. Dra. Ticiana Sidorenko de Oliveira Capote

Examinador: Prof. Dr. Carlos Alberto dos Santos Cruz

Araraquara, 07 de Maio de 2010. 


\section{Dados Curriculares}

\section{Cármen Regina Coldebella}

$\begin{array}{ll}\text { Nascimento: } & \text { 26 de Junho de } 1977 \\ \text { Naturalidade: } & \text { Campo Grande - MS } \\ \text { Filiação: } & \text { Hilário Pedro Coldebella } \\ & \text { Nadir Xavier Coldebella } \\ \text { 1997-2000 } & \text { Curso de Graduação em Odontologia - Universidade } \\ & \text { Federal de Mato Grosso do Sul-UFMS. } \\ & \text { Curso de Especialização em Odontopediatria - Faculdade } \\ & \text { de Odontologia de Araçatuba - FOA da Universidade } \\ & \text { Estadual Paulista - UNESP. } \\ & \text { Curso de Pós-graduação em Ciências Odontológicas, área } \\ & \text { de concentração em Odontopediatria - Nivel Mestrado - } \\ & \text { Faculdade de Odontologia de Araraquara - FOAr } \\ & \text { Universidade Estadual Paulista - UNESP. } \\ & \text { Curso de Pós-graduação em Ciências Odontológicas, área } \\ & \text { de concentração em Odontopediatria - Nível Doutorado - } \\ & \text { Faculdade de Odontologia de Araraquara - FOAr } \\ & \text { Universidade Estadual Paulista - UNESP. } \\ & \end{array}$


"São as crianças que, sem falar, nos ensinam as razões para viver. Elas não têm saberes a transmitir. No entanto, elas sabem o essencial da vida.

Quem não muda sua maneira adulta de ver e sentir e não se torna como criança jamais será sábio." 



\section{Dedicatória}

Dedico este trabalho aos grandes amores de minha vida...

... aos meus preciosos pais, Nadir e Hilário, e amadas irmãs, Cátia e Carine,

que com sua singela sabedoria me ensinaram que não deve se esperar pelas oportunidades e sim ir em busca delas; que o trabalho é uma terapia maravilhosa, aliás a melhor de todas. E acima de tudo demonstraram com seus atos que de nada adianta ser luz se não conseguir iluminar o caminho de quem está ao meu lado.

... ao Alan, luz da minha vida, razão do meu viver.

Por ter me mostrado que os sonhos só existem para se tornarem realidade. Sua honestidade e hombridade me encantam, você é meu Norte e meu Sul, meu porto seguro. Seu sorriso, seu olhar... são tudo para mim.

Foram vocês que me esninaram que o amor não é algo que se dá querendo retribuição, antes disso é uma filosofia de vida. Sem vocês teria sido muito mais difícil esse dia chegar, foram vocês que me apoiaram, dando-me suporte, ouvindome, incentivando-me. Aliás sem vocês teria sido muito comlpicado viver. A vocês todo meu AMOR! 


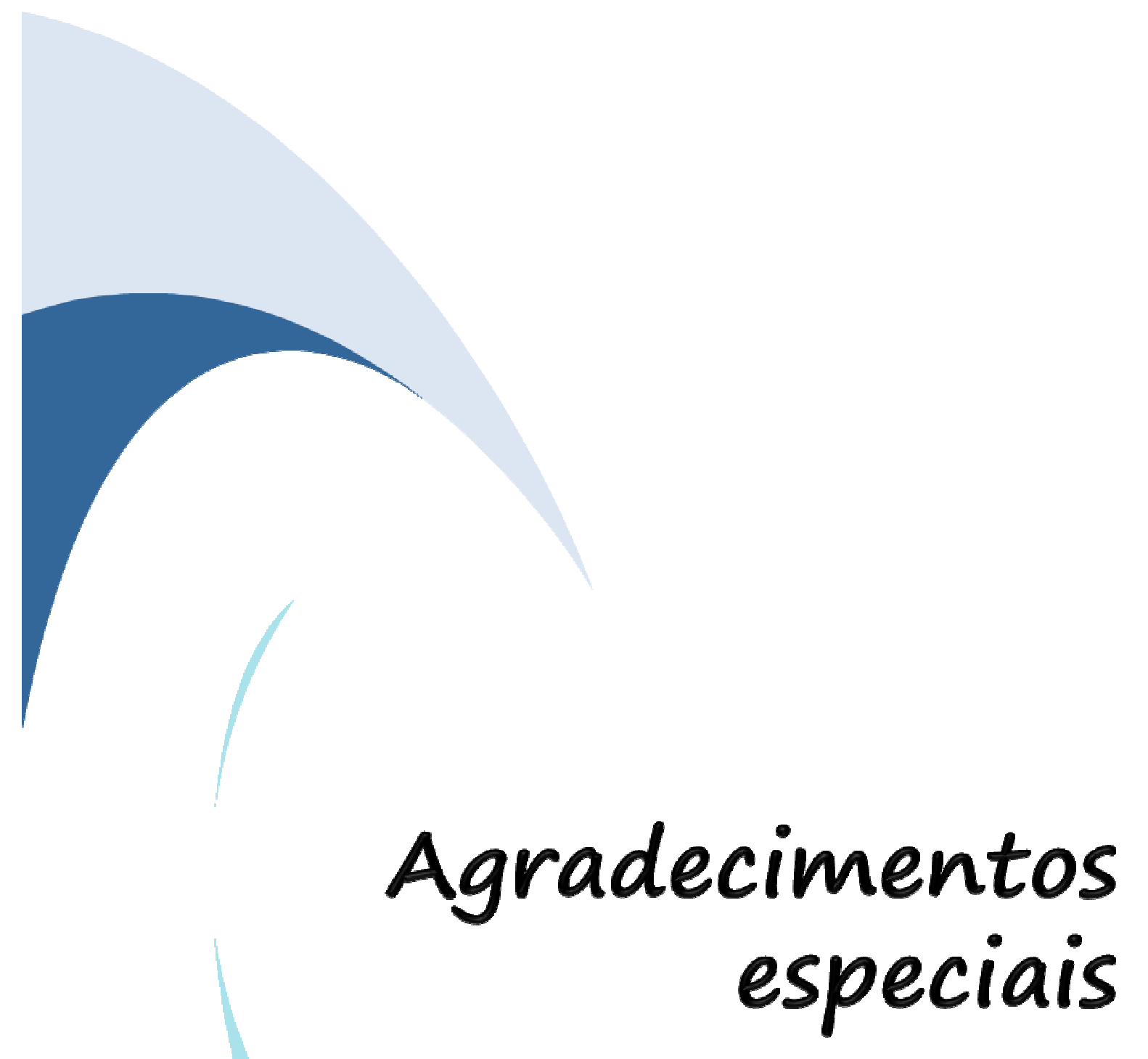




\section{À Deus}

Eu vos louvarei de todo o coração, Senhor,

Porque ouvistes as minhas palarras.

Na presença dos anjos eu Vos cantarei.

Ante Vosso santo templo prostar-me-ei,

E louvarei o Vosso nome, pela Vossa bondade e fidelidade,

Porque acima de todas as coisas, exaltastes o Vosso nome e Vossa promessa.

Quando Vos enfoquei, Vós me respondestes;

Fizestes crescer a força da minha alma.

Salmo 137: 1-4

Paí...

Hoje termina mais uma etapa da minha, ainda longa, caminhada. Em muitos momentos essa jornada foi árdua e com curvas sinuosas, mas Você sempre esteve ao meu lado, apoiando-me e fazendo com que tudo se tornasse suportável. Só Você conhece minhas capacidades e limitaçôes. Seu infinito amor por mim foi fundamental, sua companhia inestimável. 
Obrigada pelas lágrimas derramadas e pelas pedras no caminho. Foram elas que me fizeram mais forte, afinal tinha que removêlas para seguir adiante e quando a força me faltou, Você mesmo de uma forma ou de outra tirou-as do caminho para mim. Tudo foi acontecendo de forma tão simples, mas ao mesmo tempo tão bem ordenada.

Mas sobretudo obrigada pelas risadas sinceras, sorrisos homestos, amizades verdadeiras, pelos bons momentos que para sempre levarei comigo. Sempre foi tão generoso e bondoso comigo, sempre colocou anjos em minha vida no momento em que eu mais precisei.

Sei que as palarras nunca conseguirão expressar minha gratidão por tudo que Você fez e continua a fazer por mim, não canso de agrgdecer pelas graças que sempre me foram dadas, MUITO OBRIGADA. 
À Cris

Obrigada por há alguns anos atràs ter aceitado o desafio de receber $e$ acolher como orientada uma completa desconhecida: eu! Sempre serei grata pela contribuição inestimável à minha formação pessoal, profissional e acadêmica. Obrigada pela paciência, atenção e exemplo dado, que para sempre levarei. 
À Vó Morena (in memorian)

Para a senhora que sempre torceu por mim, e a todo momento fazia suas novenas "- para que você vá bem nos exames", o meu muito obrigada. A senhora faz parte dessa conquista, mas acima de tudo a senhora faz muita falta. Sua benção vó.

À madrinha Nilsa

Por estar desde 0 inicio presente em minha vida acadêmica, sempre se preocupando comigo, com meu bem-estar, sempre tão zelosa. Essa é mais uma conquista nossa. 


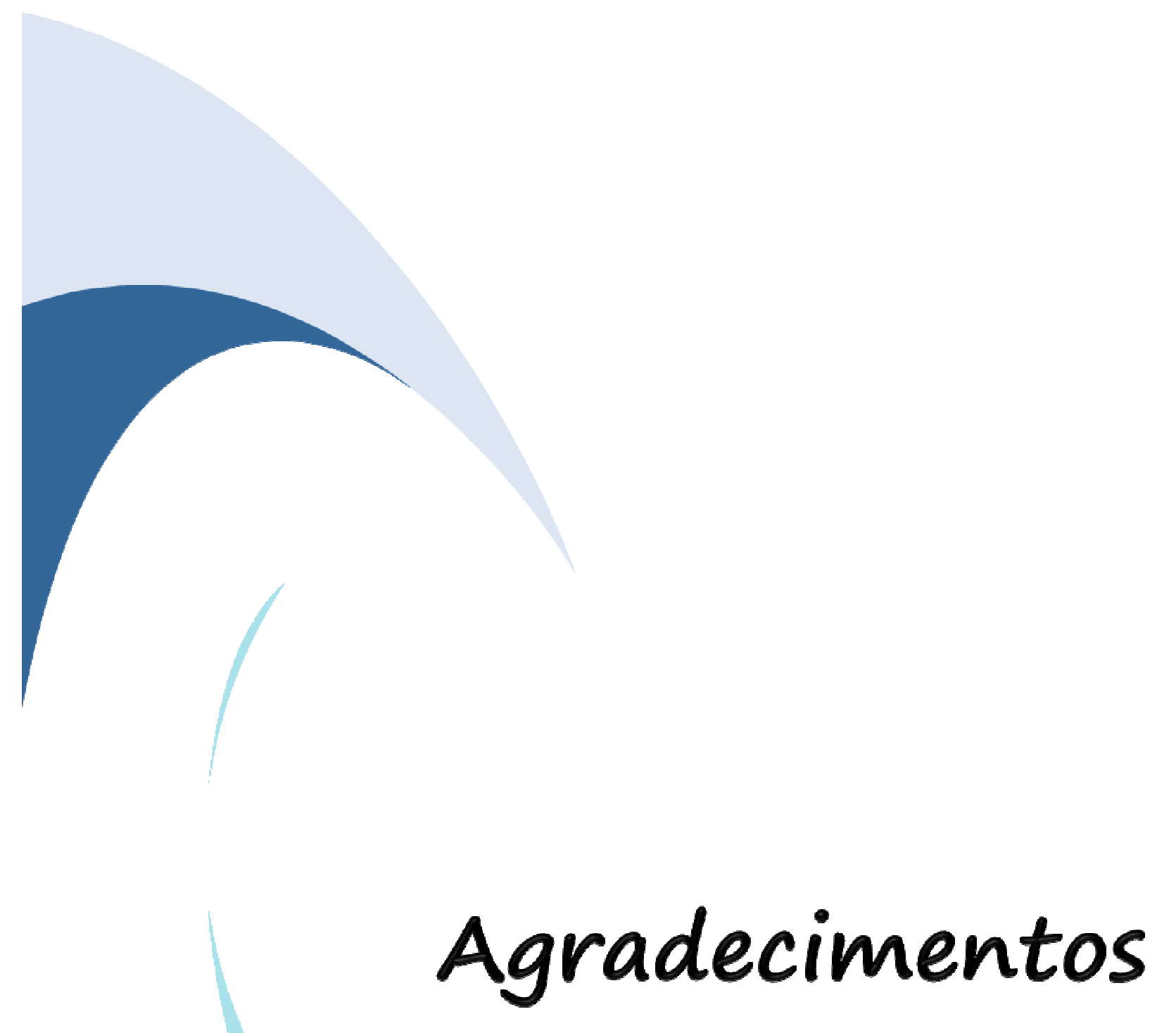


À Faculdade de Odontologia de Araraquara - Universidade Estadual Paulista, representados pelo digníssimo Diretor. Prof. Dr. José Cláudio Martins Segalla e pela Vice - Diretora Profa. Dra. Andréia Affonso Barretto Montandon;

À Coordenação da Pós - Graduação em Ciências Odontológicas da Faculdade de Odontologia de Araraquara - FOAr - UNESP, representadas pelos Profa. Dra. Josimeri Hebling e Prof. Dr. Luiz Gonzaga Gandini;

Ao Departamento de Clínica Infantil da Faculdade de Odontologia de Araraquara - UNESP representada pelo Chefe de Departamento Prof. Dr. Luiz Gonzaga Gandini e Vice-chefe Profa. Dra. Angela Cristina Cilense Zuanon; 
À CAPES pela concessão de bolsa de estudo para realização deste trabalho;

Aos professores da Disciplina de Odontopediatria da Faculdade de Odontologia de Araraquara - FOAr - UNESP, Angela Cristina Cilense Zuanon, Cyneu Aguiar Pansani, Elisa Maria Aparecida Giro, Fabio César Braga de Abreu e Lima, Josimeri Hebling, Lourdes Aparecida Martins dos Santos-Pinto e Rita de Cássia Loiola Cordeiro, pela experiência e ensinamentos passados;

Aos funcionários do Departamento de Clínica Infantil da Faculdade de Odontologia de Araraquara - FOAr - UNESP, Totó, Pedrinho, Dulce, Soninha, Thania, Cris, Márcia e Odete, pela convivência diária; 
Aos funcionários da Secretaria de Pós - Graduação da Faculdade de Odontologia de Araraquara - FOAr - UNESP, Mara, Rosângela, Flávia e Alexandre, pela atenção, dedicação e carinho no atendimento a nós alunos;

Aos queridos funcionários da Biblioteca Maria Helena, Marley,

Ceres, Odete, Silvia, Adriano, Eliane, Inês, pelo pronto atendimento, simpatia, alegria e sempre muita disposição;

Aos professores da Disciplina de Materiais Dentários Prof. Dr. Carlos Cruz, Prof. Dr. Luís Geraldo Vaz, Prof. Dr. Gelson Luis Adabo, Profa. Dra. Renata Garcia Fonseca, por disponibilizarem os aparelhos para a realização deste trabalho, além dos conhecimentos transmitidos; 
À Profa. Dra. Denise Madalena Palomari Spolidório, por

disponibilizar o espaço físico do laboratório de Microbiologia e estar sempre pronta a ajudar, pela generosidade em ceder seu tempo e conhecimentos;

À Profa. Dra. Josimeri Hebling, por emprestar 0 dispositivo para a confecção do segundo trabalho;

Ao Prof. Lourenço Correr-Sobrinho, por ter aberto as portas do Laboratório de Materiais Dentários da Faculdade de Odontologia de Piracicaba, UNICAMP, pela utilização do rugosímetro e máquina de escovação, fundamentais para a realização deste trabalho, e ao técnico Marcos B. Cangiani, por sua gentileza, generosidade, receptividade e assistência sempre que se fez necessária; 
Aos colegas da Pós-Graduação que já estão trilhando seus próprios caminhos Paula Jacques, Célia Lanza, Cris Duque, Renata Silva, Luciana Lima, Junia, Andreza Aranha, Hermes, por compartilharem experiências;

À minha turma de Pós-Graduação que me acompanha desde o mestrado Juliana Gondim, Michele Baffi Diniz, Nancy Tomoko Sacono e Simone Di Salvo Mastrantonio, pelas dificuldades compartilhadas;

Aos colegas de Pós-Graduação em Odontopediatria Ana Luiza Botta Oliveira, Camila Fávero de Oliveira, Elcilane Azevedo, Hérica Adad Hicci, Cristiane Maria da Costa Silva, Débora Lopes Salles Scheffel, Fabiano Jeremias, Juliana Feltrin de Souza, Márcia Hirome Tanaka, Amanda Fontana, Ana Paula Silveira Turrioni, Beatriz Ferraz dos Santos, Camila Maria Bullio Fragelli 
Luciana Bianchi, Margateh da Mata, Natália Apolinário de Lima, Thalita Baldieri, pelo convívio diário;

Aos amigos do Laboratório de Patologia experimental Nancy, Ana Paula, Diana, Juliana Pirola, pelas discussões científicas realizadas no laboratório;

À Maga, por compartilhar bons momentos, pelas idas e vindas de São Carlos, pelas nossas conversas;

À Amandita, vizinha querida e fiel;

À Laine, pelos anos de convivência; 
Aos meus queridos professores da UFMS, que abriram as portas para um mundo até então totalmente desconhecido para mim, a Odontologia. Cumpriram sua missão com maestria.

À Professora Dalva Terra, modelo constante de honestidade, seriedade, honradez e dignidade. Se resolvi seguir o caminho da Odontopediatria foi devido ao seu grande exemplo.

À familia Kalife Coelho, pelo carinho com que me receberam desde o início, não se importando com a distância, e pela constante presença em minha vida;

Aos meus familiares, família Xavier (carinhosamente conhecida como Família X) e família Coldebella, meu muito obrigada pela torcida, e por entenderem a minha ausência, é muito bom poder contar com vocês; 
Aos queridos amigos de Araraquara Marco, Pedro e Tici.

Sentirei MUITO a falta de vocês que tornaram esses dias muito mais alegres e fácies;

Aos anjos que Deus colocou em minha vida nestes últimos anos

Emi, Márcia, Michele e Dulce. Por terem me escutado e estimulado.

Pelas boas e muitas risadas. Pelo incentivo para que eu não desistisse no meio do caminho. Vocês foram muito importante e por isso ouso Thes dirigir estas palavras

"O valor das coisas não está no tempo em que elas duram, mas na intensidade com que elas aconteceram...

Por isso existem momentos inesqueciveis, coisas inexplicáveis e pessoas incomparáveis..."

A todos aqueles que contribuiram de forma direta $e$ indireta para a realização deste trabalho. 



\section{SUMÁRIO}

RESUMO 23

$\begin{array}{ll}\text { ABSTRACT } & 27\end{array}$

$\begin{array}{ll}\text { INTRODUÇÃO } & 30\end{array}$

$\begin{array}{ll}\text { PROPOSIÇÃO } & 36\end{array}$

CAPÍTULO $1+39$

$\begin{array}{ll}\text { CAPÍTULO } 2 & 59\end{array}$

$\begin{array}{ll}\text { CAPÍTULO } 3 & 80\end{array}$

$\begin{array}{ll}\text { CONSIDERAÇÕES FINAIS } & 98\end{array}$

$\begin{array}{ll}\text { REFERENNCIAS } & 103\end{array}$ 

Coldebella CR. Efeito da aplicação de ondas de ultrassom sobre cimentos de ionômero de vidro e dentina subjacente [Tese de Doutorado] Araraquara: Faculdade de Odontologia da UNESP; 2010.

\section{RESUMO}

Proposição: O objetivo deste trabalho, dividido em três estudos, foi investigar o efeito após a aplicação de ondas de ultrassom sobre cimentos de ionômero de vidro (CIV) (1) a dureza da dentina subjacente, hígida e afetada por cárie; (2) a resistência de união à dentina hígida e afetada por cárie (3) e à rugosidade do material após ensaio de escovação. Materiais e métodos: Nos três estudos foram utilizados os CIV Vitremer (VT) e Ketac Molar Easymix (KM). Para o estudo 1 foram realizados preparos cavitários ( $3 \mathrm{~mm}$ de largura, 5 $\mathrm{mm}$ de comprimento e $2 \mathrm{~mm}$ de profundidade) na face vestibular de 80 incisivos bovinos. Foi realizada a indução de lesão de cárie artificial pelo método microbiológico $(n=40)$. Os dentes foram distribuídos em 8 grupos

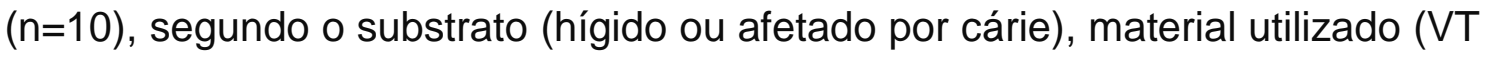
ou KM) e o tratamento recebido (com ou sem a aplicação de ondas de ultrassom). A aplicação de ondas de ultrassom foi realizada por 30 segundos. Após 30 dias de armazenagem em água os dentes foram seccionados e as 
leituras de dureza Knoop realizadas na dentina subjacente ao material até 200 $\mu \mathrm{m}$ de distância da interface dentina/CIV. No segundo estudo foram confeccionados 20 blocos de dentina bovina para cada material, sendo que 10 deles foram submetidos ao processo de indução de lesão de cárie artificial e subsequente remoção da dentina contaminada. Em cada bloco foram confeccionados dois corpos de prova com $1,5 \mathrm{~cm}$ de altura e $3 \mathrm{~cm}$ de diâmetro, sendo o primeiro com e o segundo sem a aplicação de 30 segundos de ondas de ultrassom. Após 24 horas, os corpos de prova foram submetidos ao ensaio mecânico de cisalhamento. No terceiro trabalho 32 espécimes de cada material, VT e KM, foram confeccionados em matriz de dente bovino, sendo que a metade recebeu ondas de ultrassom durante a presa inicial. A rugosidade superficial foi avaliada após 24 horas $(n=16)$ e 30 dias $(n=16)$ de manipulação do material, antes e após ensaio de escovação. Para análise estatística dos estudos foram utilizados os testes ANOVA e Tukey, com nível de significância de 5\%. Resultados: A dentina hígida apresentou melhores resultados de dureza e resistência à adesão quando comprada àquela afetada por cárie. A aplicação de ondas de ultrassom proporcionou maiores valores de dureza e aumento na resistência de união para as duas superfícies dentinárias. Esses resultados foram observados para ambos materiais. Pôde-se observar que com a aplicação de ondas de ultrassom os CIV apresentaram menor rugosidade superficial apenas quando avaliados após 24 horas de sua manipulação. Conclusão: Pôde-se concluir que a aplicação de ondas de ultrassom sobre CIV é uma boa opção, pois se mostrou eficiente em aumentar a dureza da dentina hígida, favorecer a remineralização da dentina afetada por cárie, promover melhor adesão de CIV a esses dois substratos dentinários e 
proporcionar menor rugosidade superficial do material após 24 horas de sua manipulação.

Palavras-Chave: Cimentos de ionômero de vidro, ultrassom, dureza, resistência ao cisalhamento, desgaste de resturação dentária, escovação dentária, dentina, cárie dentária. 

Coldebella CR. Effect of ultrasound application on glass ionomer cement and underlying dentin [Tese de Doutorado]. Araraquara: Faculdade de Odontologia da UNESP; 2010

\section{ABSTRACT}

Aim: This work was divided into three studies. The objective was to investigate the effect of ultrasound application on glass ionomer cement (GIC), analyzing underlying dentin hardness, bond strength to noncarious dentin and cariesaffected dentin and the material roughness after toothbrushing test. Materials and methods: GIC Vitremer (VT) and Easymix Ketac Molar (KM) were used in these studies. In the first study, cavities ( $3 \mathrm{~mm}$ wide, $5 \mathrm{~mm}$ in length and $2 \mathrm{~mm}$ deep) were performed on the buccal surface of eighty bovine incisors. Microbiological method was used to induce artificial caries lesions $(n=40)$. The teeth were divided into 8 groups $(n=10)$, according the substrate (noncarious dentin or caries-affected dentin), the material used (VT or KM) and the treatment received (with or without ultrasound application). The ultrasound application was performed for 30 seconds, and teeth stored in water for 30 days. After that, the specimens were sectioned and transversal hardness evaluation was performed in the underlying dentin material up to depth of 200 $\mu \mathrm{m}$. In the second study, 20 dentin blocks were used for each material. Ten of them were artificially decayed and performed subsequent removal of infected 
dentin. In each block, two specimens $(1.5 \mathrm{~cm}$ high and $3 \mathrm{~cm}$ diameter) were performed, the first with and the second without ultrasound application. After 24 hours the specimens were shear bonding tested. For the third study 32 specimens of each material, VT and KM, were prepared using a bovine tooth matrix. Half of them received a $30 \mathrm{~s}$ ultrasound application during its initial setting. The surface roughness, before and after toothbrushing test, was evaluated at 24 hours $(n=16)$ and 30 days $(n=16)$. Data were analyzed by ANOVA and Tukey tests. For all the studies, the statistical tests were considered at the present level of significance of $5 \%$. Results: Noncarious dentin showed better results of hardness and bond strength when compared with caries-affected dentin. The ultrasound application showed higher hardness values and increased the bond strength for both dentin studied. These results were observed for both materials. The 24 hours-handling GICs showed higher roughness compared to 30 days-handling. It was observed that ultrasound application decreased surface roughness of 24 hours-handling GICs. Conclusion: The ultrasound application affected in vitro glass-ionomer cements properties. It was efficient in increasing the hardness of noncarious dentin and caries-affected dentin, improving the remineralization of cariesaffected dentin. It was capable to provide better adhesion of GICs to these two dentin substrates and decrease surface roughness of the material after 24 hours-handling.

Key words: glass ionomer cements, ultrasound, hardness, shear strength, dental restorative wears, toothbrushing, dental caries. 



\section{INTRODUÇÃO}

Os cimentos de ionômero de vidro (CIV) foram introduzidos na Odontologia há mais de 30 anos (Kent et al. ${ }^{21}, 1973$ ) e desde então têm sofrido modificações em sua formulação visando a melhora de suas properiedades físicas e mecânicas. Consistem basicamente de uma solução aquosa de ácido poliacrílico, a qual reage com um pó de vidro de fluoraluminosilicato (Hotz et al. $\left.{ }^{19}, 1977\right)$. A reação de presa do material ocorre devido à formação de ligações cruzadas entre o ácido policarboxílico com íons $\mathrm{Ca}^{++}$e/ou $\mathrm{Al}^{+++}$ resultando na geleificação e formação da matriz do cimento (Crisp, Wilson ${ }^{6}$, 1974). A formação do gel é um processo lento e melhora, com o passar do tempo, as propriedades mecânicas do material (Pearson, Atkinson ${ }^{36}$, 1991; Towler et al. ${ }^{50}, 2001$; Yap et al. $\left.{ }^{60}, 2003\right)$. Os CIV possuem propriedades satisfatórias tais como biocompatibilidade (Hatton et al. ${ }^{17}$, 2006; Nicholson, Czarnecka $\left.{ }^{34}, 2008\right)$, adesão à estrutura dentária $\left(\right.$ Ngo et al. ${ }^{33}, 1997$; Sennou et al. ${ }^{41}$, 1999; Yip et al. ${ }^{61}, 2001$; Glasspoole et al. $^{15}, 2002$ ), coeficiente de expansão térmica similar ao do dente (Nassan, Watson ${ }^{32}$, 1998), além de possuir a importante característica de liberação de flúor (DeSchepper et al. ${ }^{9}$, 1989; Loyola-Rodriguez et al. ${ }^{26}$, 1994; Meiers, Miller ${ }^{28}$, 1996; Nicholson ${ }^{34}$, 1998). 
A adesão química às estruturas do dente têm sido relatada como uma das principais vantagens do material (Frankenberger et al. ${ }^{13}, 1997$; Fukuda et al. ${ }^{14}, 2003$; Yap et al. $\left..^{60}, 2003\right)$. O processo de adesão do material à dentina é complexo, pois ao contrário do esmalte, esta contem grande quantidade de água e de material orgânico. Estudos tem sido realizados com o objetivo de tornar a adesão mais efetiva e durável (Swift et al. ${ }^{43}$, 1995; Algera et al. ${ }^{1}, 2005$; Choi et al. ${ }^{4}, 2006$; Lim et al. $\left.{ }^{25}, 2009\right)$. Uma das formas para avaliar a união à estrutura dentária é a utilização de ensaios mecânicos, como o de cisalhamento, o qual é relatado por Braga et $\mathrm{al}^{2}$. (2010) como um método ainda amplamente utilizado diante da facilidade de execução.

O mecanismo de adesão do CIV à estrutura dental é baseado em uma reação de troca iônica do material com o esmalte e a dentina, mais precisamente entre íons cálcio da hidroxiapatita, e os grupos carboxílicos do cimento (Mount ${ }^{31}$, 1999; Fukuda et al. $^{14}, 2003$ ). Esta união torna-se mais resistente e durável com o passar do tempo devido ao contínuo processo maturação do material (Ngo et al. $^{33}$, 1997; Yap et al. ${ }^{60}$, 2003). Estudos demonstram que os valores alcançados na adesão do CIV à dentina variam entre 3,16 e 5,81 MPa, após uma semana, de 5,00 e 14,95 MPa após um mês de espatulação do material (Yap et al. ${ }^{60}, 2003$ ). Esses resultados são observados em dentina hígida, que nem sempre corresponde à situação encontrada na clínica (Czarnecka et al. $\left.{ }^{7}, 2007\right)$.

Sabe-se que freqüentemente os CIV são inseridos sobre dentina afetada por cárie, passível de remineralização. Assim a liberação de flúor $\left(\right.$ Mjör $^{30}, 1996$; Yap et al. $\left.{ }^{59}, 2003\right)$ também é uma característica importante do material, pois promove ação anticariogênica e cariostática, que é capaz de 
alterar o crescimento e metabolismo microbiano de Streptococos mutans e Lactobacilos remanescentes em dentina cariada (Hamilton ${ }^{16}$, 1990; Weerheijm et $\left.a{ }^{55}, 1999\right)$. O efeito antibacteriano é proporcional à quantidade de flúor liberada (Wiegand et al. ${ }^{56}, 2007$ ), a qual ocorre em grande quantidade nas primeiras 24 horas e decresce dentro de 10 a 20 dias até se tornar constante (DeSchepper et al. ${ }^{10}, 1991$; Seppä et al. ${ }^{42}, 1995$; Vermeersch et al. ${ }^{53}, 2001$ ).

A ação cariostática deve-se à capacidade de redução da desmineralização, aumento da remineralização e até mesmo promoção da hipermineralização da dentina subjacente (ten Cate, van Duinen ${ }^{48}$, 1995), que pode ser observada por meio do aumento dos valores da dureza dentinária sob o material (Santiago et al. $\left.^{40}, 2005\right)$. Deste modo, o teste de dureza é considerado uma ferramenta viável e confiável para predizer a capacidade remineralizadora do material.

Os CIV também apresentam limitações clínicas, devido a sua lenta reação de presa, como a sensibilidade à umidade e a possibilidade de sofrer desidratação, as quais podem prejudicar sua resistência mecânica (Liberman et al. ${ }^{24}$, 1990; Pereira et al. ${ }^{37}, 2002$ ). Apresentam também baixa resistência ao desgaste (Hse et al. ${ }^{20}, 1999$ ), a qual pode promover maior rugosidade superficial, favorecendo o acúmulo de biofilme bacteriano e consequente aumento do risco de desenvolvimento da lesão de cárie e de doença periodontal (Rios et al. ${ }^{38}, 2002$ ).

Muitas características físicas e químicas dos CIV foram melhoradas, embora ainda apresentem o fenômeno de sinérese e embebição durante os períodos iniciais da reação de presa (Wilson ${ }^{52}$, 1990; McLean et 
al. ${ }^{27}$, 1994; Cattani-Lorente et al. ${ }^{3}$, 1999). Na tentativa de aumentar a velocidade de tal reação e assim melhorar a resistência mecânica inicial do material (Wiegand et al. ${ }^{56}, 2007$ ), surgiram algumas alternativas como a incorporação de monômeros resinosos ao produto, dando origem aos CIV modificados por resina (Wilson ${ }^{52}$, 1990; McLean et al. ${ }^{27}, 1994$; Christensen ${ }^{5}$, 1997; Cattani-Lorente et al. ${ }^{3}$, 1999). Os CIV também sofreram alterações tanto na proporção pó/líquido assim como no tamanho das partículas, encontrados nos CIV restauradores de alta viscosidade (Yap et al. ${ }^{59}, 2003$ ).

Outro método para a acelerqação da resação de presa inicial é a aplicação de ondas de ultrassom na superfície do material (Towler et al. ${ }^{50}$, 2001; Towler et al. ${ }^{51}$, 2003; Kleverlaan et al. ${ }^{22}$, 2004; Twomey et al. ${ }^{52}, 2004$; Algera et al. ${ }^{1}, 2005$; Fagundes et al. ${ }^{11}, 2006$; Tanner et al. ${ }^{45}$, 2006; Rushe, Towler $^{39}, 2006$; Talal et al. ${ }^{44}, 2009$ ). Embora não se conheça ao certo o mecanismo de ação das ondas de ultrassom sobre os CIV (Davidson $\left.{ }^{8}, 2006\right)$, tem-se considerado a atividade cavitacional (Towler et al. ${ }^{51}, 2003$; Tanner et al. ${ }^{45}, 2006$; Rushe, Towler $\left.^{39}, 2006\right)$, a qual promove aumento da temperatura local (Algera et al. ${ }^{1}, 2005$; Kleverlaan et al. ${ }^{22}, 2004$ ) devido a formação e colapso de bolhas no interior do material (Laird, Walmsley ${ }^{23}$, 1991). Tem sido observado também a quebra do aglomerado de partículas de vidro (Towler et al. ${ }^{51}, 2003$; Fagundes et al. $\left.{ }^{11}, 2006\right)$, o que permite melhor mistura do líquido com o pó (Towler et al. ${ }^{51}, 2003$; Tanner et al. ${ }^{45}, 2006$ ), devido ao íntimo contato das mesmas (Fagundes et al. ${ }^{11}, 2006$ ). O efeito causado pelas ondas de ultrassom é dependente do tempo de aplicação (Talal et al. ${ }^{44}, 2009$ ), assim como, das características do CIV que está sendo avaliado (Tanner et al. ${ }^{45}$, 2006; Talal et al. $\left.{ }^{44}, 2009\right)$. 
A aplicação de ondas de ultrassom tem se mostrado eficiente em proporcionar melhores propriedades físicas aos CIV (Towler et al. ${ }^{51}, 2003$; Twomey et al. ${ }^{52}$, 2004; Kleverlaan et al..$^{22}$, 2004; Algera et al. ${ }^{1}, 2005$; Fagundes et al. $\left.{ }^{11}, 2006\right)$, efeito notado principalmente nas primeiras 24 horas após a manipulação do material (Towler et al. ${ }^{51}, 2003$; Kleverlaan et al. ${ }^{22}$, 2004). Permite a aceleração da reação de presa (Towler et al. ${ }^{50}, 2001$; Towler et al. ${ }^{51}$, 2003; Talal et al. ${ }^{44}, 2009$ ), o que promove maior resistência às forças mastigatórias num período de tempo mais curto (Yap et al. ${ }^{60}$, 2003) e possivelmente menor rugosidade superficial do material. Observa-se também aumento dos valores de resistência à compressão (Kleverlaan et al. $\left.{ }^{22}, 2004\right)$, diminuição da absorção de água (Fagundes et al. ${ }^{11}, 2006$ ), capacidade de melhorar a união do CIV ao esmalte (Algera et al. ${ }^{1}$, 2005) e à dentina hígida (Fagundes et al. ${ }^{11}, 2006$ ) e diminuir as porosidades internas do material (Towler et al. $\left.{ }^{51}, 2003\right)$.

Diante da possibilidade da utilização de ondas de ultrassom para melhorar as propriedades dos CIV, torna-se importante conhecer os efeitos de sua aplicação na resistência de adesão à dentina, na dureza da dentina afetada por cárie subjacente ao material, assim como na rugosidade superficial do CIV. 



\section{PROPOSIÇÃO GERAL}

Avaliar propriedades mecânicas e físicas de Cimentos de lonômero de Vidro (dureza da dentina subjacente, resistência de união e rugosidade superficial) após a aplicação de ondas de ultrassom durante sua reação inicial de presa.

\section{PROPOSIÇÃO ESPECÍFICA}

Capítulo 1: Dureza da dentina hígida e cariada subjacente a Cimentos de Ionômero de Vidro submetidos à aplicação de ondas de ultrassom.

Avaliar os valores de dureza em dois substratos, dentina hígida e cariada, subjacente a Cimentos de lonômero de Vidro que receberam a aplicação de ondas de ultrassom durante sua reação inicial de presa. 
Capítulo 2: Resistência de união de Cimentos de lonômero de Vidro, após aplicação de ondas de ultrassom, à dentina.

Avaliar a resistência à dentina hígida e afetada por cárie, de Cimentos de lonômero de Vidro que receberam a aplicação de ondas de ultrassom durante sua reação inicial de presa.

Capítulo 3: Rugosidade superficial de Cimentos de lonômero de Vidro submetidos à aplicação de ondas de ultrassom: Avaliação após diferentes períodos de maturação .

Avaliar a influência da aplicação de ondas de ultrassom durante a reação de presa inicial na rugosidade superficial de Cimentos de lonômero de Vidro após ensaio de escovação, utilizando dois períodos de maturação do material, 24 horas e 30 dias. 

Dureza da dentina hígida e cariada subjacente à Cimentos de Inômero de Vidro submetidos à aplicação de ondas de ultrassom.

Cármen Regina Coldebella * Angela Cristina Cilense Zuanon*

* Faculdade de Odontologia de Araraquara - Universidade Estadual Paulista [UNESP]. Araraquara, São Paulo, Brasil.

Título curto: Uso de ultrassom em Cimentos de lonômero de vidro e dureza da dentina subjacente.

Palavras-chave: ultrassom; cimento de ionômero de vidro; cárie dentária, dentina; dureza.

Autor correspondente:

Profa. Dra. Angela Cristina Cilense Zuanon

Departamento de Clínica Infantil

Faculdade de Odontologia de Araraquara - UNESP

R: Humaitá, 1680, Centro. CEP:14801-903, Araraquara-SP Tel:[16] 3301-6335.

e-mail: aczuanon@foar.br

Não existem conflitos de interesse. 

O objetivo deste trabalho foi avaliar a dureza da dentina hígida (DH) e afetada por cárie (DC) subjacente a dois cimentos de ionômero de vidro (CIV), um convencional (Ketac Molar Easymix - KM) e outro modificado por resina (Vitremer - VT), após a aplicação de ondas de ultrassom (US) durante sua reaçõ inicial de presa. Foram confeccionados preparos cavitários na face vestibular de 80 incisivos bovinos os quais foram distribuídos em 8 grupos, segundo o substrato e o tratamento: 1-KM DH sem US; 2-KM DC sem US; 3KM DH com US; 4-KM DC com US, 5-VT DH sem US; 6-VT DC sem US; 7-VT DH com US; 8-VT DC com US. A indução de lesão de cárie artificial foi promovida pelo método microbiológico com Streptococcus mutans e a aplicação de US sobre os CIV foi realizada por 30 s. Após 30 dias de armazenagem em água os corpos de prova foram seccionados no sentido mesio-distal e as leituras de dureza realizadas até a profundidade de $200 \mu \mathrm{m}$ da interface material/substrato. Os dados foram analisados pelos testes estatísticos de ANOVA e de Tukey $(\alpha=0,05)$. A dentina hígida apresentou melhores resultados quando comparada àquela afetada por cárie. Além disso a aplicação de US proporcionou maiores valores de dureza para os dois materiais e para as duas superfícies estudadas. Pôde-se concluir que a aplicação de US aumentou a dureza da dentina hígida e favorecer a remineralização da dentina afetada por cárie. 


\section{Introdução}

Embora a doença cárie dentária tenha diminuído nos últimos tempos ainda é vista como o maior problema de saúde pública bucal no Brasil. Considerando o poder de remineralização da estrutura dentária, a conservação da estrutura e da polpa dental e até mesmo a praticidade e viabilidade, a remoção parcial do tecido cariado tem sido indicada para a realização de preparos mais conservativos [Mount e Ngo , 2000], durante a técnica de tratamento restaurador atraumático (ART), [Maltz et al., 2002, Massara et al., 2002] e no capeamento pulpar indireto [Marchi et al., 2008], diminuindo os riscos de possível exposição pulpar [Maltz et al., 2002, Kidd, 2004, Duque et al., 2009]. Nessas situações, apenas a dentina infectada é removida o que torna possível a preservação da dentina afetada, passível de remineralização [Ngo et al., 1997]. A técnica conservativa de remoção de tecido cariado apresenta altas taxas de sucesso clínico, pois permite mudanças no remanescente dentinário afetado pela cárie resultando em uma dentina escurecida e com consistência endurecida, além de promover signifcante redução da microbiota local [Kidd 2004, Duque et al., 2009].

Dessa forma é desejável que sobre esse substrato sejam aplicados produtos que tenham adequado efeito antibacteriano. Isso se torna possível diante da utilização de materiais que além de permitirem um bom selamento da cavidade, e consequentemente restrição de suplemento do substrato, possuam a capacidade de liberação de flúor [van Amerongen 1996]. O uso de cimentos odontológicos que liberam flúor começou com o cimento de silicato que apresenta em sua composição compostos de fluoretos e sais de cálcio. A partir desse material foram desenvolvidos os cimentos de ionômero de vidro (CIV) [Wilson, 1996].

Os CIV são capazes de inibir o crescimento in vitro de algumas espécies de bactérias orais [De Schepper et al., 1989; Loyola-Rodriguez, et al., 1994; Herrera et al., 2000, Duque et al., 2009] devido ao baixo pH que apresentam durante sua reação inicial de presa e a liberação de flúor [DeSchepper et al., 1989; Loyola-Rodriguez et al., 1994; Meiers e Miller, 1996] o qual também é 
capaz de interferir no processo dinâmico de desmineralização e remineralização do tecido dental, onde o segundo predomina e é considerado o principal seu mecanismo anticariogênico do flúor [Delbem e Cury, 2002].

Estudos demonstram o efeito da liberação do flúor do CIV sobre o esmalte dentário [Delbem e Cury, 2002, Martins et al., 2006] sendo este menor a medida em que se distancia da interface material/esmalte [Hotta et al., 2001; Martins et al., 2006]. Porém pouco tem se estudado sobre a influência do material sobre a dentina cariada. Sabe-se que durante sua reação inicial de presa o CIV apresenta maior liberação de flúor, com significante queda após esse período [Vermeersch et al., 2001; Martins et al., 2006], tornando-se insuficiente para exercer efeito antibacteriano após 6 semanas de sua inserção [Seppä et al., 1995].

A reação de presa do CIV é considerada lenta [Talal et al., 2009], o que torna o material mais susceptível à absorção de água. Diante desta dificuldade surgiram alternativas como a incorporação de monômeros resinosos aos CIV (CIVMR) que promovem também boa adesão à estrutura dental [Wilson 1996] sem contudo interferir em propriedades como a liberação de flúor [Meiers e Miller, 1996; Herrera et al., 2000]. Recentemente a literatura relata o uso de ondas de ultrassom com o objetivo de acelerar a reação de presa do CIV [Towler et al., 2001, Twomey et al., 2004]. A técnica oferece ainda a capacidade de melhorar a adesão do material tanto ao esmalte [Algera et al., 2005] quanto a dentina hígida [Fagundes et al., 2006], sem a necessidade de incorporação de produtos químicos adicionais ao material [Towler et al., 2001], porém pouco se sabe sobre sua influência na liberação de flúor.

O objetivo desse estudo foi avaliar a dureza da dentina hígida e cariada bovina, subjacente à CIV submetidos à aplicação de ondas de ultrassom. A hipótese nula testada é que não existe diferença na dureza da dentina (hígida ou afetada por cárie) subjacente aos CIV que receberam a aplicação de ondas de ultrassom.

\section{Materiais e métodos}

\section{Obtenção dos Espécimes}


Foram utilizados para cada material, 40 incisivos bovinos hígidos, com ausência de defeitos estruturais, extraídos de gado da raça Nelore, com idade média de 30 meses. Os dentes foram limpos, as coroas separadas das raízes com auxílio de uma cortadeira metalográfica (Isomet 1000 - Buehler Ltda., Lake Bluff, II, EUA) sob refrigeração e as câmaras pulpares seladas com resina composta micro-híbrida fotopolimerizável (Filtek ${ }^{T M}$ Z250 - 3M ESPE, St. Paul, $M M$, EUA) em incrementos de no máximo $2 \mathrm{~mm}$ e polimerizados com luz halógena (Ultralux, Dabi Atlante, Ribeirão Preto, SP, BR).

Sobre a face vestibular de cada dente foi realizado um preparo cavitário de $3 \mathrm{~mm}$ de largura, $5 \mathrm{~mm}$ de comprimento e $2 \mathrm{~mm}$ de profundidade a uma distância de $3 \mathrm{~mm}$ da junção amelo-cementária, utilizando ponta diamantada cilíndrica ㄲo 1036 (KG Sorensen Ind. Com. Ltda., Barueri, SP, Brasil). A padronização das cavidades foi obtida por meio de um dispositivo eletromecânico (SENAI - Araraquara/ Pós-graduação em Odontopediatria da Faculdade de Odontologia de Araraquara - UNESP).

\section{Produção de lesão de cárie artificial na superfície dentinária}

Para cada material, 20 dentes foram submetidos ao protocolo de indução de cárie artificial com microrganismos. Para que apenas a superfície da dentina desenvolvesse a lesão de cárie artificial, os dentes receberam uma camada de adesivo epóxi (Aradilte Professional 24 horas - Brascola, São Bernardo do Campo-SP, BR) e subsequentemente aplicação de uma camada de esmalte de unha (Colorama, CEIL Com. Exp. Ind. Ltda., São Paulo, BR). Em seguida, cada dente foi suspenso por meio de um fio ortodôntico, em uma tela metálica adaptada a abertura de um béquer preenchido com $250 \mathrm{~mL}$ de água destilada e o conjunto foi autoclavado a $120^{\circ} \mathrm{C}, 1 \mathrm{kgf} / \mathrm{cm}^{2}$, por 20 minutos. Os dentes foram então imersos em uma solução cariogênica contendo $3,7 \mathrm{~g}$ de BHI (Acumedia Manufactures Inc, Lasing Michigan, EUA), $1 \mathrm{~g}$ de glicose anidra (LabSynth Produtos para Laboratório, Ltda., São Paulo - SP, BR), 2 g de sacarose (LabSynth Produtos para Laboratório, Ltda., São Paulo - SP, BR) e $0,5 \mathrm{~g}$ de extrato de levedura (Acumedia Manufactures Inc, Lasing Michigan, EUA) para cada $100 \mathrm{~mL}$ de água. Foram utilizados $25 \mathrm{~mL}$ de solução por dente. Essa solução foi previamente inoculada com $2 \%$ de Streptococcus 
mutans ATCC25175 (Coleção de Culturas Tropical Fundação André Toselo) (10 $\mathrm{UFC} / \mathrm{mL}$ ). Os espécimes permaneceram nessa solução por 14 dias em jarras de microanaerofilia, sendo que a cada 48 horas era feita a troca da solução, contudo sem nova inoculação de microrganismos. Após esse período os dentes foram novamente autoclavados.

\section{Remoção da dentina cariada}

Após a remoção do biofilme com gaze, e dos materiais isolantes com lâminas de bisturi, a dentina infectada por cárie foi removida com auxílio de brocas esféricas de aço de $n^{\circ} 4$ (KG Sorensen, SP, B R). A cada quatro dentes, novas brocas foram utilizadas. A dentina amolecida foi removida até a obtenção de uma dentina mais endurecida e resistente quando submetida a leve pressão exercida por uma sonda exploradora .

O grupo de dentina hígida passou pela etapa de esterilização em autoclave, e recebeu sobre sua superfície a mesma aplicação de broca esférica durante o período de 60 segundos, objetivando dessa forma a obtenção de smear layer.

As superfícies dentinárias dos dois grupos (hígido e afetado por cárie) foram lavadas com jato de água/ar, secas com auxílio de papel absorvente e divididas conforme demonstrado na Tabela 1.

\section{Procedimento restaurador e aplicação de ondas de ultrassom}

Foram utilizados dois CIV, um convencional e outro modificado por resina (Tabela 2). O condicionamento da dentina e manipulação dos materiais foram realizados de acordo com as instruções do fabricante e inseridos nas cavidades com auxílio de uma seringa Centrix (Centrix, Shelton, EUA). Logo após os materiais foram cobertos por uma tira de poliéster (Quimidrol, Joinvile, SC, BR). Os grupos 3, 4, 7 e 8 receberam a aplicação de ondas de ultrassom, realizada por um período de 30 segundos sem irrigação. A ponta ativa do aparelho deslizou sobre toda a superfície do CIV e do elemento dental. O equipamento de ultrassom empregado foi o PROFI III BIOS (Dabi Atlante, 
Ribeirão Preto, SP, BR), utilizando $80 \%$ de sua potência e a ponta do aparelho foi a Perio Sub (Dabi Atlante, Ribeirão Preto, SP, BR).

Para os CIVMR ainda foi realizada a polimerização com aparelho de luz halógena (Ultralux, Dabi Atlante, Ribeirão Preto, SP, BR) com intesidade de $510 \pm 10 \mathrm{~mW} / \mathrm{cm}^{2}$ por um período de 40 segundos. Em seguida todos os corpos receberam proteção superficiale foram armazenados.

\section{Ensaio mecânico de dureza}

Após armazenagem por 30 dias em água destilada a $37^{\circ} \mathrm{C}$ os dentes foram seccionados no sentido mesio-distal em máquina de corte metalográfica, dividindo a restauração em 2 partes iguais. A secções incisal foi embebida em resina acrílica, ficando a superfície de corte totalmente livre do material. Esta superfície foi polida em politriz com lixas de carbeto de silício em granulações decrescentes de abrasividade (320,600, 1200 e 1500) e na sequência com pastas diamantadas com granulações 6,3 e $1 \mu \mathrm{m}$. Entre essas etapas os espécimes foram submetidos a banhos em cuba ultrassônica, pelo período de 1 minuto.

As medidas de dureza Knoop foram realizadas por meio de um microdurômetro (Buehler Ltd., Lake Bluff, II, EUA), empregando-se carga de 25 $\mathrm{g}$ durante 15 segundos. As leituras foram realizadas em cinco pontos lineares a $25,50, \quad 100,150$ e $200 \mu m$ de distância da interface material restaurador/substrato dentinário. Em cada secção foram realizadas três seqüências de leituras na parede pulpar do espécime, sendo uma na região central do espécime e as outras duas a $1000 \mu \mathrm{m}$ de cada lado da medida central. A média das leituras foi obtida para determinar a dureza Knoop. As leituras foram realizadas por um mesmo operador treinado.

\section{Análise estatística}

Para a análise estatística foi utilizado o software SPSS versão 17.0. Os dados foram tabulados e aos valores de dureza obtidos foram aplicados os testes estatísticos de análise de variância a três critérios fixos (material vs. substrato dentinário vs. uso de ultrassom). Para comparações múltiplas foi 
utilizado teste de Tukey quando a hipótese nula de igualdade foi rejeitada. Todos os testes foram considerados ao nível de significância de 5\%.

\section{Resultados}

Pôde-se observar que o material restaurador não apresentou significância para as interações, devendo o mesmo então ser isolado nas comparações.

Os valores para a dureza da dentina, hígida e afetada por cárie, subjacente ao Ketac Molar Easymix com e sem aplicação de ondas de ultrassom encontram-se na Tabela 3. A aplicação de ondas de ultrassom sobre esse CIV promoveu aumento da dureza da dentina hígida assim como da afetada por cárie. Também para esse material pôde-se observar que em todas as situações estudadas a dureza da dentina hígida sempre foi superior à afetada por cárie.

Os valores para a dureza da dentina hígida e afetada por cárie, subjacentes ao Vitremer com e sem aplicação de ondas de ultrassom encontram-se na Tabela 4. Pôde-se observar que a aplicação de ondas de ultrassom interferiu positivamente na dureza dos dois tipos de dentina, sendo que a hígida apresentou maiores valores quando comparada à afetada por cárie.

\section{Discussão}

Para avaliar a dureza da dentina hígida e afetada por cárie foram utilizados dentes de boi, uma vez que os mesmos são considerados um substrato adequado quando realiza-se indução artificial de cárie dental [Hara et al., 2003]. Considerando que o Streptococcus mutans é uma das bactérias mais frequentemente relacionadas com a cárie dental [Fraga et al., 1996], tem a capacidade de manter sua atividade metabólica em ambientes com baixo $\mathrm{pH}$ [Maltz et al., 2002] e geralmente é encontrada sob as restaurações após a 
remoção incompleta do tecido cariado [De Schepper et al., 1989, Maltz et al., 2002], neste estudo foi utilizado o método de indução de lesão de cárie artificial por meio desse microrganismo.

As propriedades mecânicas da dentina estão relacionadas ao seu conteúdo mineral e a perda deste é diretamente proporcional à diminuição de sua dureza [Angker et al., 2003]. Durante a progressão do porcesso carioso pode ser notada considerável perda mineral [Little et al., 1965]. Desta forma, as medidas da dureza da dentina são consideradas um importante ferramenta para verificar alterações superficiais relacionadas com a lesão de cárie [Hosoya et al., 2000] e são indicadas para avaliar o grau de mineralização desse tecido [Hotta et al., 2001, Hosoya et al., 2000, Santiago et al., 2005]. Assim durante a realização deste estudo a dureza Knoop foi utilizada para avaliar a dentina hígida e cariada.

Em todas as condições estudadas a dureza subjacente aos CIV da dentina afetada por cárie foi significantemente menor quando comparada com a dentina hígida, assim como relatado pela literatura [Hosoya et al., 2000, Santiago et al., 2005]. O tecido dentinário afetado por cárie apresenta-se com menor conteúdo mineral devido a sua desmineralização parcial [Wang et al., 2007]. A remoção de dentina cariada infectada promove condições favoráveis para a remineralização da dentina afetada [Marchi 2008] que intencionalmente é preservada [Marchi 2008, Duque et al., 2009]. Estudos [Pinto et al., 2006, Maltz et al., 2002, Bjørndal e Larsen, 2000, Massara et al., 2002, Duque et al., 2009] demonstram, que a remoção parcial de cárie e adequado selamento da cavidade, mudanças na consistência dentinária, tornando-a um tecido mais duro e com menor quantidade de microrganismos, o que indica seu poder de remineralização. Sabendo que a consistência da dentina é um parâmetro clínico importante para limitar a remoção da dentina irreversivelmente desnaturada, infectada e não mineralizada [Kidd, 2004, Marchi et al., 2008], nesse estudo a cárie foi removida até se encontrar um tecido de consistência firme ao toque.

O efeito cariostático decorrente da utilização de CIV, que contém flúor em sua composição, é comprovado [Seppä et al., 1995; Vermeesch et al., 2005]. Embora maior liberação de flúor ocorra na fase inicial, após sua inserção na cavidade [Vermeersch et al., 2001], com duas semanas de maturação nota- 
se uma apreciável incorporação de íons flúor na camada superficial da dentina [Knight et al., 2006]. Baseando-se nos resultados de Hotta et al. (2001), os quais observaram aumento significativo na mineralização após 30 dias de aplicação de CIV, este estudo também utilizou este mesmo período de tempo para avaliar a dureza da dentina subjacente ao material. Em 12 semanas ten Cate e van Duinen (1995) observaram que o CIV teve a capacidade de hipermeniralizar a dentina subjacente.

Sabe-se que a quantidade de flúor liberada varia de acordo com o tipo de CIV empregado [Rushe e Towler, 2006]. Neste estudo pôde-se observar aumento na dureza tanto com a utilização do CIV convencional quanto do CIVMR. A razão mais provável do efeito antibacteriano do CIV está relacionada à queda do $\mathrm{pH}$ do meio ao redor do material [Vermeersch et al., 2005, Duque et al., 2009] associado a liberação de flúor [Vermeersch et al., 2005, Thanjal et al., 2010], que altera o crescimento e metabolismo eletrolítico do Streptococcus Mutans [Seppä et al., 1992]. O flúor também promove o endurecimento do remanescente dentinário após a remoção parcial da lesão de cárie [Massara et al., 2002], com o aumento do conteúdo mineral na dentina adjacente e/ou subjacente a restaurações com CIV indicando um significante potencial de remineralização desse material [Massara et al., 2002, ten Cate e van Duinen, 1995]. O baixo pH do CIV durante sua reação de presa contribui mais para suas propriedades antibacterianas do que a própria liberação de flúor [Vermeersch et al., 2005]. Sabendo-se que existe uma relação direta entre acidez do material (baixo pH superficial) e a inibição do crescimeno de Streptococcus Mutans [Vermeersch et al., 2005], sugere-se que ao acelerar a reação de presa do CIV, as propriedades antibacterianas poderiam ser negativamente alteradas.

Neste estudo foi observado que após a aplicação de ondas de ultrassom sobre os CIV Ketac Molar Easymix e Vitremer maiores valores para a dureza da dentina, hígida e afetada por cárie, subjacente aos mesmos foram alcançados. A aceleração na reação de presa [Towler et al., 2001, Kleverlaan et al., 2004], o aumento da dureza [Towler et al., 2001], da adesão ao esmalte [Algera et al., 2005] e da resistência a compressão [Kleverlaan et al., 2004] tem sido em parte atribuído ao aumento de temperatura que a aplicação de ondas de ultrassom promove [Towler et al., 2003, Kleverlaan et al., 2004, 
Algera et al., 2005]. Embora a literatura demonstre que a aplicação de ondas de ultrassom aumente a liberação de flúor [Rushe and Towler 2006, Thanjal et al., 2010], este efeito não pode ser exclusivamente atribuído ao aumento de temperatura [Thanjal et al., 2010], uma vez que Woolford e Grieve (1995) demonstraram que a aplicação de radiação infravermelha prejudicou a liberação deste íon.

Os resultados encontrados nesse estudo provavelmente ocorreram devido à capacidade do ultrassom em quebrar, por meio da atividade cavitacional, as partículas de vidro [Towler et al., 2003], reduzindo assim o tamanho médio das mesmas, e consequentemente aumentando a área de superfície para a reação entre o pó e o líquido. Desta forma, maior quantidade de íons flúor fica disponível para ser liberado e difundido. Além disso, as ondas de ultrassom promovem maior movimentação de partículas dentro da matriz [Tanner et al., 2006], o que também pode melhorar a difusão do flúor. Embora a aplicação de ondas de ultrassom possa proporcionar diferentes resultados diante de diferentes tipos de CIV [Talal et al., 2009], no presente estudo maior dureza na dentina foi observada para os dois CIV, tanto para o convencional, quanto para o modificado por resina.

Assim, a hipótese nula foi negada concluindo-se que o efeito de ondas de ultrassom sobre os CIV promove melhora na dureza da dentina subjacente ao material, hígida ou afetada por cárie, atuando desta forma como importante coadjuvante no processo de remineralização.

\section{Agradecimentos}

Os autores agradecem a Profa. Denise Madalena Palomari Spolidório, pela utilização do Laboratório de Microbiologia da Faculdade de Odontologia de Araraquara e a Coordenação de Aperfeiçoamento de Pessoal de Ensino Superior (CAPES) pela concessão de bolsa de estudo. 


\section{Referências}

Algera TJ, Kleverlaan CJ, Gee AJ, Prahl-Andersen B, Feilzer AJ. The influence of accelerating the setting rate by ultrasound or heat on the bond strength of glass ionomers used as orthodontic bracket cements. Eur $\mathrm{J}$ Orthod 2005;27:472-476.

Angker L, Swain MV, Kilpatrick N. Micromechanical characterization of the properties of primary tooth dentine. J Dent 2003;31:261-267.

Bjørndal L, Larsen T. Changes in the cultivable flora in deep carious lesions following a stepwise excavation procedure. Caries Res 2000;34:502-508.

De Schepper EJ, Thrasher MR, Thurmond BA. Antibacterial effects of glass ionomers. Am J Dent 1989;2:51-56.

Delbem AC, Cury JA. Effect of application time of APF and NaF gels on microhardness and fluoride uptake of in vitro enamel caries. Am J Dent 2002;15:169-172.

Duque C, Negrini TC, Sacono NT, Spolidorio DM, de Souza Costa CA, Hebling J. Clinical and microbiological performance of resin-modified glass-ionomer liners after incomplete dentine caries removal. Clin Oral Investig 2009;13:465471.

Fagundes TC, Barata TJ, Bresciani E, Cefaly DF, Carvalho CA, Navarro MFL. Influence of ultrasonic setting on tensile bond strength of glass-ionomer cements to dentin. J Adhes Dent 2006;8:401-407.

Fraga RC, Siqueira JF Jr, de Uzesa M. In vitrro evaluation of antibacterial effects of photo-cured glass ionomer liners and dentin bonding agents during setting. J Prosthet Dent 1996;76:484-486.

Hara AT, Queiroz CS, Paes Leme AF, Serra MC, Cury JA. Caries Progression and Inhibition in Human and Bovine Root Dentine in situ. Caries Res 2003;37:339-344. 
Herrera M, Castillo A, Bravo M, Liebana J, Carrion P. Antibacterial activity of resin adhesives, glass ionomer and resin-modified glass ionomer cements and a compomer in contact with dentin caries samples. Oper Dent 2000;25:265269.

Hosoya Y, Marshall SJ, Watanabe LG, Marshall GW. Microhardness of carious deciduous dentin. Oper Dent 2000;25:81-89.

Hotta M, Li Y, Sekine I. Mineralization in bovine dentin adjacent to glassionomer restorations. J Dent 2001;29:211-215.

Kidd EAM. How "clean" must a cavity be before restoration? Caries Res 2004;38:305-313.

Kleverlaan CJ, Van Duinen RNB, Feilzer AJ. Mechanical properties of glass ionomer cements affected by curing methods. Dent Mater 2004;20:45-50.

Knight GM, McIntyre JM, Craig GG, Mulyani. Ion uptake into demineralized dentine from glass ionomer cement following pretreatment with silver fluoride and potassium iodide. Aust Dent J 2006;51:237-241.

Little MF, Dirksen TR, Schlueter G. The $\mathrm{Ca}, \mathrm{P}, \mathrm{Na}$, and Ash content at different depths in caries. J Dent Res 1965;44:362-35.

Loyola-Rodriguez JP, Garcia-Godoy F, Lindquist R. Growth inhibition of glass ionomer cements on mutans streptococci. Pediatr Dent 1994;16:346-349.

Maltz M, de Oliveira EF, Fontanella V, Bianchi R. A clinical, microbiologic, and radiographic study of deep caries lesions after incomplete caries removal. Quintessence Int 2002;33:151-159.

Marchi JJ, Froner AM, Alves HLR, Bergmann CP, Araújo FB. Analysis of Primary Tooth Dentin after Indirect Pulp Capping. J Dent Child 2008;75:295300.

Martins LRM, Silva ALF, Cury JA, Francischone CE. Liberação de Flúor de Restaurações de lonômero de Vidro e a sua incorporação ao esmalte dental após ciclos de desmineralização/remineralização. Rev Odonto Ciênc 2006;21:30-36. 
Massara MLA, Alves JB, Brandão PRG. Atraumatic restorative treatment: clinical, ultrastructural and chemical analysis. Caries Res 2002;36:430-436.

Meiers JC, Miller GA. Antibacterial activity of dentin bonding systems, resinmodified glass ionomers, and polyacid-modified composite resins. Oper Dent 1996;21:257-264.

Mount GJ, Ngo H. Minimal intervention: a new concept for operative dentistry.Quintessence Int 2000;31:527-533.

Ngo H, Ruben J, Arends J, White D, Mount GJ, Peters MC, Faller RV, Pfarrer A. Electron probe microanalysis and transverse microradiography studies of artificial lesions in enamel and dentin: a comparative study. Adv Dent Res 1997;11:426-432.

Pinto AS , Araujo FB, Franzon R, Figueiredo MC, Hendz S, Garcia-Godoy F, Maltz M. Clinical and microbiological effect of calcium hydroxide protection in indirect pulp capping in primary teeth. Am J Dent 2006;19:382-386.

Rushe N, Towler MR. The influence of ultrasonic setting on fluoride release from glass polyalkenoate cements. J Mater Sci 2006;41:5775-5777.

Santiago BM, Ventin DA, Primo LG, Barcelos R. Microhardness of dentine underlying ART restorations in primary molars: an in vivo pilot study. $\mathrm{Br}$ Dent $\mathrm{J}$ 2005;199:103-106.

Seppä L, Korhonen A, Nuutinen A. Inhibitory effect on S. mutans by fluoridetreated conventional and resin-reinforced glass ionomer cements. Eur $\mathrm{J}$ Oral Sci 1995;103:182-185.

Seppä L, Torppa-Saarinen E, Luoma H. Effect of different glass ionomers on the acid production and electrolyte metabolism of Streptococcus mutans Ingbritt. Caries Res 1992;26:434-438.

Talal A, Tanner KE, Billington R, Pearson GJ. Effect of ultrasound on the setting characteristics of glass ionomer cement studied by Fourier Transform Infrared Spectroscopy. J Mater Sci: Mater Med 2009;20:405-411. 
Tanner DA, Rushe N, Towler MR. Ultrasonically set glass polyalkenoate cements for orthodontic applications. J Mater Sci: Mater Med 2006;17:313-318.

ten Cate JM, van Duinen RN. Hypermineralization of dentinal lesions adjacent to glass-ionomer cement restorations. J Dent Res 1995;74:1266-1271.

Thanjal N.K, Billington RW, Shahid S, Luo J, Hill RG, Pearson GJ. Kinetics of fluoride ion release from dental restorative glass ionomer cements: the influence of ultrasound, radiant heat and glass composition. J Mater Sci Mater Med 2010;21:589-595.

Towler MR, Bushby AJ, Billington RW, Hill RG. A preliminary comparison of the mechanical properties of chemically cured and ultrasonically cured glass ionomer cements, using nano-indentation techniques. Biomaterials $2001 ; 22: 1401-1406$.

Towler MR, Crowley CM, Hill RG. Investigation into the ultrasonic setting of glass ionomer cements. part I. postulated modalities. J Mater Sci Lett 2003;22:539-41.

Twomey E, Towler MR, Crowley CM, Doyle J, Hampshire S. Investigation into the ultrasonic setting of glass ionomer cements. Part II: Setting times and compressive strengths. J Mater Sci 2004;39:4631-4632.

van Amerongen WE. Dental caries under glass ionomer restorations. J Public Health Dent 1996;56[3 Spec No]:150-4;161-3.

Vermeersch G, Leloup G, Vreven J. Fluoride release from glass-ionomer cements, compomers and resin composites. J Oral Rehabil. 2001;28:26-32.

Vermeersch G, Leloup G, Delmée M, Vreven J. Antibacterial activity of glassionomer cements, compomers and resin composites: relationship between acidity and material setting phase. J Oral Rehabil 2005;32:368-374.

Wang Y, Spencer P, Walker MP. Chemical profile of adhesive/caries-affected dentin interfaces using Raman microspectroscopy. J Biom Mater Res 2007;81A:279-286. 
Wilson AD. A hard decade's work: steps in the invention of the glass-ionomer cement . J Dent Res 1996;75:1723-1727.

Woolford MJ; Grieve AR. Release of fluoride from glass polyalkenoate (ionomer) cement subjacent to radiant heat. J Dent 1995;23:233-237. 


\section{Tabelas}

Tabela 1: Divisão dos grupos experimentais e material de acordo com 0 substrato e tratamento utilizado.

\begin{tabular}{|c|c|c|c|c|}
\hline Grupo & CIV & Substrato & $\mathbf{N} \circ$ de dentes & Tratamento \\
\hline 1 & \multirow{4}{*}{$\begin{array}{c}\text { Ketac Molar } \\
\text { Easymix }\end{array}$} & Hígido & 10 & Sem ultrassom \\
\hline 2 & & Cariado & 10 & Sem ultrassom \\
\hline 3 & & Hígido & 10 & Com ultrassom \\
\hline 4 & & Cariado & 10 & Com ultrassom \\
\hline 5 & \multirow{4}{*}{ Vitremer } & Hígido & 10 & Sem ultrassom \\
\hline 6 & & Cariado & 10 & Sem ultrassom \\
\hline 7 & & Hígido & 10 & Com ultrassom \\
\hline 8 & & Cariado & 10 & Com ultrassom \\
\hline
\end{tabular}

Tabela 2: Material, composição (principais componentes) e proporção dos CIV.

\begin{tabular}{|c|c|c|}
\hline CIV & Principais componentes & $\begin{array}{c}\text { Proporção } \\
\text { pó/liquido } \\
\text { (mg/mL) }\end{array}$ \\
\hline $\begin{array}{l}\text { Ketac Molar } \\
\text { Easymix }^{\mathrm{TM}} \\
\text { [3M ESPE, St. Paul, } \\
\text { MN, EUA] }\end{array}$ & $\begin{array}{l}\text { Pó: vidro de aluminio-calcio- } \\
\text { lantânio fluorosilicato glasse ácido poliacrílico } \\
\text { Líquido: água, ácido polietileno policarbônico e } \\
\text { ácido tatárico }\end{array}$ & $4.5 / 1$ \\
\hline $\begin{array}{c}\text { Vitremer }^{\text {MR }} \\
\text { [3M ESPE, St. Paul, } \\
\text { MN, EUA] }\end{array}$ & $\begin{array}{l}\text { Primer: HEMA, álcool etílico, copolímero de } \\
\text { ácido acrílico e itacônico } \\
\underline{\text { Pó: }} \text { vidro de Fluor-aluminosilicato, } \\
\text { potassium persulfate, ácido ascorbico } \\
\text { Líquido: copolímero do ácido poliacrílico e } \\
\text { itacônico, água, HEMA }\end{array}$ & $2.5 / 1$ \\
\hline
\end{tabular}

Abreviaturas: HEMA: 2-hidroxi-etil-dimetacrilato. 
Tabela 3: Médias e desvio padrão dos valores de dureza nos grupos experimentais do material Ketac Molar Easymix.

\begin{tabular}{lcc}
\hline \multirow{2}{*}{ Tipo de Dentina } & \multicolumn{2}{c}{ Uso de Ultrasom } \\
\cline { 2 - 3 } & Não & Sim \\
\hline HíGIDA & $41,4 \pm 4,932 \mathrm{Aa}$ & $49,0 \pm 5,838 \mathrm{Ba}$ \\
\hline CARIADA & $30,9 \pm 4,704 \mathrm{Ab}$ & $33,6 \pm 3,814 \mathrm{Bb}$
\end{tabular}

Letras maiúsculas (na horizontal) e minúsculas (na vertical) diferentes demonstram diferenças estatísticas significantes entre os grupos.

Tabela 4: Médias e desvio padrão dos valores de dureza nos grupos experimentais do material Vitremer.

\begin{tabular}{lcc}
\hline \multirow{2}{*}{ Tipo de Dentina } & \multicolumn{2}{c}{ Uso de Ultrasom } \\
\cline { 2 - 3 } & & Não \\
\hline HÍGIDA & $41,5 \pm 4,294 \mathrm{Aa}$ & $46,2 \pm 4,218 \mathrm{Ba}$ \\
\hline CARIADA & $30,7 \pm 4,972 \mathrm{Ab}$ & $31,9 \pm 4,042 \mathrm{Bb}$
\end{tabular}

Letras maiúsculas (na horizontal) e minúsculas (na vertical) diferentes demonstram diferenças estatísticas significantes entre os grupos. 

Resistência de união de Cimentos de lonômero de Vidro, após aplicação de ondas de ultrassom, à dentina.

Cármen Regina Coldebella *

Angela Cristina Cilense Zuanon**

* Aluna de doutorado do curso de pós-graduação em Ciências Odontológicas área Odontopediatria do Departamento de Clínica Infantil da Faculdade de Odontologia de Araraquara - UNESP. Rua Humaitá, 1680, Centro, 14801-903 Araraquara, SP, Brasil.

** Profa. Livre-docente da Disciplina de Odontopediatria do Departamento de Clínica Infantil da Faculdade de Odontologia de Araraquara - UNESP. Rua Humaitá, 1680, Centro, 14801-903 Araraquara, SP, Brasil.

Autor correspondente:

Profa. Dra. Angela Cristina Cilense Zuanon

Departamento de Clínica Infantil

Faculdade de Odontologia de Araraquara - UNESP

R:Humaitá, 1680 - Centro. CEP: 14801-903, Araraquara-SP Tel: (16)3301-6335 E-mail:aczuanon@foar.br

Artigo formatado segundo as normas da Journal of Adhesive Dentistry 
Resumo

Objetivo: O objetivo deste trabalho foi avaliar, por meio de ensaio de cisalhamento, a resistência de união à dentina hígida e afetada por cárie de um CIV convencional e outro modificado por resina, após a aplicação de ondas de ultrassom. Materiais e métodos: Foram confeccionados 20 blocos de dentina bovina para cada material, sendo que a metade foi submetida ao processo microbiológico de indução de lesão de cárie. Os blocos foram divididos em grupos de acordo com material utilizado, Ketac Molar Easymix ou Vitremer, e com o substrato, dentina hígida ou afetada por cárie. Sobre a dentina (hígida ou afetada por cárie), em cada bloco foram realizados dois corpos de prova, o primeiro com e o segundo sem a aplicação de ondas de ultrassom, por 30 segundos. Os blocos de dentina foram armazenados por 24 horas e em seguida submetidos ao ensaio mecânico de cisalhamento. Para a avaliação dos dados foram utilizados os teste de ANOVA (três critérios) e Tukey $(\alpha=0,05)$. Resultados: Os resultados demonstraram maiores valores de resistência de união a ambos substratos após a aplicação de ondas de ultrassom, tanto para o Ketac Molar Easymix como para o Vitremer. Conclusão: Pôde-se concluir que a aplicação de ondas de ultrassom foi eficiente em promover melhor adesão dos CIV à dentina hígida e à afetada por cárie.

Palavras-chave: ultrassom; cárie dentária; dentina; resistência ao cisalhamento. 


\section{Introdução}

Um dos maiores desafios na Odontologia tem sido a busca por um material restaurador ideal, que possua propriedades similares àquelas da estrutura dental. Neste sentido, os cimentos de ionômero de vidro (CIV) apresentam algumas vantagens como a adesão a estrutura dental (Wilson e Kent, 1972; Glasspoole, et al., 2002), sendo o único material que apresenta união química ao dente (Fukuda, et al., 2003). Estudos revelam evidências da presença de uma camada intermediária ao longo da interface CIV-dentina e CIV-esmalte decorrente da troca iônica entre o material e a estrutura dental (Titley, et al., 1996; Ngo, et al., 1997; Sennou, et al., 1999; Abdalla, 2000).

Para que haja efetiva adesão necessita-se de contato íntimo entre o CIV e o substrato dental, uma vez que esta ocorre devido à quelação dos grupos carboxílicos do poliácido com o cálcio do esmalte e da dentina (Yoshida, et al., 2000). Desta forma, torna-se previsível que melhor adesão ocorra em esmalte, devido não só a seu maior conteúdo inorgânico como também a maior homogeneidade do ponto de vista morfológico. A dentina, ao contrário, é um tecido que contém grande quantidade de água e material orgânico, conectados à polpa por meio dos túbulos dentinários. Estes contêm em seu interior fluído dentinário, responsável pela umidade intrínseca dessa estrutura (Swift, et al., 1995). A adesão dos materiais restauradores à dentina é um porcesso complexo (Swift, et al., 1995) e tem sido amplamente estudada nas últimas décadas com o objetivo de torná-la mais efeitva e durável (Ruse e Smith, 1991; Fritz, et al., 1996; Yoshida, et al., 2000; Choi, et al., 2006).

A resistência adesiva dos CIV é menor quando comparada aos compósitos resinosos, mas a durabilidade dessa adesão parece ser maior (Tyas, 1991). Isso pode ser atribuído à natureza da interface entre o cimento e o dente (Shimada, et al., 1999), a qual com o tempo torna-se mais resistente em função de um processo de íon difusão ( $\mathrm{Ngo}$, et al., 1997). Estudos laboratoriais utilizam dentes hígidos para determinar a resistência de união (Miyazaki, et al., 1999; Wang, et al., 2006; Souza-Zaroni, et al., 2006; El Askary, et al., 2008). Porém, esses resultados nem sempre correspondem a 
situação clínica, quando muitas vezes os CIV são inseridos sobre dentina afetada por cárie.

Além da adesão às estruturas dentais, os CIV apresentam outras vantagens como a liberação de flúor (Vermeersch et al., 2001; Delbem e Cury, 2002), baixo coeficiente de expansão térmica (Naasan e Watson, 1998) e resistência à degradação na cavidade oral (Walls, 1986). São susceptíveis porém ao fenômeno de sinérese e embibição (Yap, et al., 2001) que pode alterar algumas de suas propriedades mecânicas e compormeter seu uso em áreas de grandes esforços mastigatórios (Kerby e Knobloch, 1992).

Várias modificações foram realizadas na formulação inicial dos CIV com a intenção de melhorar suas propriedades físicas. Uma delas diz respeito a incorporação de monômeros hidrófilos, como o 2-hidroxi-etil-dimetacrilato (HEMA) ao líquido, o que deu origem aos CIV modificados por resina (CIVMR) (Wilson,1990; McLean, et al., 1994). Os CIVMR apresentam desempenho clínico superior aos CIV convencionais (Wilson,1990; Cattani-Lorente, et al., 1999) mantendo as características de anticariogenicidade, devido a liberação de flúor, e compatibilidade térmica com o dente (Yelamanchili e Darvell, 2008). A presença da reação fotoquímica reduziu a sensibilidade à umidade $\mathrm{e}$ desidratação normalmente associadas com a fase inicial da reação de presa ácido-base das formulaçõs dos CIV convencionais (Yelamanchili e Darvell, 2008), promoveu também melhores condições de trabalho e adesão à dentina (Toledano, et al., 1999; Fagundes, et al., 2006).

Outra alternativa para melhorar as propriedades físicas, assim como reduzir a sensibilidade dos CIV à umidade e desidratação, é a aplicação de ondas de ultrassom sobre o material. Estudos têm demonstrado que este procedimento é capaz de reduzir o tempo de presa (Towler, et al., 2003; Twomey, et al., 2004; Kleverlaan, et al., 2004; Tanner, et al., 2006), aumentar a dureza superficial (Towler, et al., 2001), aumentar a resistência à compressão (Twomey, et al., 2004; Kleverlaan, et al., 2004; Tanner, et al., 2006), a adesão ao esmante (Algera, et al., 2005) e à dentina hígida (Fagundes, et al., 2006), sem contudo mencionar relatos relacionados a adesão em dentina cariada.

Desta maneira, torna-se importante avaliar a resistência de união de um CIV convencional e outro modificado por resina à dentina afetada por cárie, após a aplicação de ondas de ultrassom. A hipótese nula testada foi que a 
aplicação de ondas de ultrassom sobre CIV convencional e CIVMR não influencia na resistência ao cisalhamento à dentina.

\section{Materiais e métodos}

Os CIV utilizados estão relacionados na Tabela 1. Foram utilizados 20 incisivos bovinos para cada material. Após limpas, as coroas foram separadas das raízes com auxílio de uma cortadeira metalográfica (Isomet 1000 - Buehler Ltda., Lake Bluff, II, EUA) sob refrigeração. Para padronização da obtenção de superfícies de dentina completamente planas e polidas, cada dente teve sua face vestibular desgastada com lixas de carbeto de silício nas granulações 180, 320, 600 e 1200 em politriz elétrica rotativa (Metaserv 2000 - Buehler Ltda., Lake Bluff, II, EUA) sob refrigeração. Um bloco de $8 \times 6 \mathrm{~mm}$ foi obtido da face vestibular de cada coroa. Ao final deste processo os blocos de dentina, ou espécimes obtidos, foram aleatoriamente divididos em grupos de acordo com o tipo de substrato (hígido ou afetado por cárie).

\section{Produção de cárie na superfície dentinária}

Para cada material, 10 blocos de dentina foram submetidos ao protocolo de indução de cárie com microrganismos. Com o intuito de que apenas a área desejada desenvolvesse cárie artificial, todas as superfícies do bloco, com exceção da vestibular, receberam uma camada de adesivo epóxi (Aradilte Professional 24 horas - Brascola, São Bernardo do Campo-SP, Brasil) e subsequentemente aplicação de uma camada de esmalte de unha (Colorama, CEIL Com. Exp. Ind. Ltda., SP, BR). Cada bloco foi suspenso, por meio de um fio ortodôntico, em uma tela metálica adaptada a abertura de um béquer preenchido com $250 \mathrm{~mL}$ de água destilada e o conjunto autoclavado a $120^{\circ} \mathrm{C}, 1$ $\mathrm{kgf} / \mathrm{cm}^{2}$, por 20 minutos. Em seguida, foram imersos em uma solução cariogênica contendo 3,7 g de BHI (Acumedia Manufactures Inc, Lasing Michigan, EUA), $1 \mathrm{~g}$ de glicose anidra (LabSynth Produtos para Laboratório, Ltda., São Paulo - SP, Brasil), $2 \mathrm{~g}$ de sacarose (LabSynth Produtos para Laboratório, Ltda., São Paulo - SP, Brasil) e 0,5 g de extrato de levedura (Acumedia Manufactures Inc, Lasing Michigan, EUA) para cada $100 \mathrm{~mL}$ de água. No primeiro dia de contato com a solução cariogênica houve a 
inoculação com 2\% de Streptococcus mutans ATCC25175 (Coleção de Culturas Tropical Fundação André Toselo) ( $\left.10^{8} \mathrm{UFC} / \mathrm{mL}\right)$, sendo que a solução foi trocada a cada 48 horas durante 14 dias permanecendo em jarra de microanaerofilia. Após esse período os blocos de dentina foram novamente autoclavados.

Após a remoção do biofilme com gaze, e dos materiais isolantes com lâminas de bisturi, os blocos de dentina foram posicionados no interior de tubos de PVC (Tigre, Rio Claro, SP, Brasil) e inserida resina acrílica quimicamente ativada (Resina acrílica Jet Acrílico Autopolimerizante - Artigos Odontológicos Clássico Ltda., São Paulo, SP, Brasil), preenchendo todo espaço restante com o material acrílico, de modo que a superfície a ser estudada ficasse livre de resina.

O grupo correspondente à dentina hígida recebeu o mesmo tratamento exceto pela imersão em solução cariogênica.

\section{Aplicação de ondas de ultrassom e ensaio mecânico de cisalhamento}

Para a realização do ensaio de cisalhamento foi necessária a obtenção de uma superfície completamente plana. Portanto a remoção da dentina infectada por cárie foi realizada com auxílio de lixas de carbeto de silício de granulação 320 sob irrigação. Na dentina hígida, o mesmo procedimento foi realizado por um período de 30 segundos. Em cada espécime foram confeccionados 2 cilindros de CIV, sendo o primeiro com e o segundo sem aplicação de ondas de ultrassom (Tabela 2).

Os CIV foram manipulados de acordo com as instruções do fabricante (Tabela 1). Os cilindros de CIV foram confeccionados com auxílio de matrizes padronizadas de polietileno, com dimensões de $1,5 \mathrm{~mm}$ de altura por $3 \mathrm{~mm}$ de diâmetro e a área adesiva foi delimitada por meio de fita dupla face (3M do Brasil Ltda, Sumaré-SP). A aplicação de ondas de ultrassom foi realizada passando a ponta do aparelho sobre a superfície do material por 30 segundos. O equipamento de ultrassom utilizado foi o PROFI III BIOS (Dabi Atlante, Ribeirão Preto, SP, Brasil) sem irrigação, e a ponta utilizada foi a Perio Sub. Para o CIVMR foi realizada também a polimerização com luz halógena (Ultralux, Dabi Atlante, Ribeirão Preto, SP, BR) por 40 segundos, com intesidade de $510 \pm 10 \mathrm{~mW} / \mathrm{cm}^{2}$. 
Após o confecção dos cilindros de CIV, os espécimes foram armazenados em $100 \%$ de umidade relativa do ar, a $37^{\circ} \mathrm{C}$ por 24 horas para então serem submetidos ao teste de resistência adesiva por meio do ensaio de cisalhamento.

Os espécimes foram acoplados a um dispositivo apropriado e montados em Máquina Universal de Ensaios Mecânicos Emic (DL10000 - EMIC Equipamentos e Sistemas de Ensaio Ltda, São José dos Pinhais, PR, Brasil), com célula de carga de $1 \mathrm{kN}$ e velocidade do atuador de $0,5 \mathrm{~mm} / \mathrm{min}$. A força de cisalhamento foi exercida através de um fio metálico de $0,2 \mathrm{~mm}$ de diâmetro lançado como prolongamento da célula de carga, de modo que os cilindros de CIV permaneceram alinhados a esta célula. O fio manteve contato com 0 semicírculo inferior do cilindro de CIV e com a superfície dentinária. O movimento foi cessado no momento da ruptura dos corpos de prova e esse valor registrado por meio de um software (Test Works - Sistema Test Star 2 MTS Systems Corporation - Minneapolis - Minnesota - EUA). Os valores finais de resistência adesiva foram calculados dividindo-se a carga máxima em Newton (N) pela área de união dos espécimes, sendo expresso em MPa.

Após o teste de cisalhamento, a análise das fraturas foi realizada com lupa estereoscópica (Modelo SZX7, Olympus, São Paulo, Brasil) e classificadas em (1) coesiva (fraturas que ocorreram dentro CIV ou na dentina); (2) adesiva (fratura entre o CIV e a dentina) e (3) mista (combinação da fratura adesiva e coesiva).

\section{Análise Estatística}

Aos valores de resistência de união ( $\mathrm{MPa}$ ) obtidos foram aplicados os testes estatísticos de análise de variância a três critérios fixos (material vs. substrato dentinário vs. uso de ultrassom). Para comparações múltiplas foi utilizado teste de Tukey quando a hipótese nula de igualdade foi rejeitada. Todos os testes foram considerados ao nível de significância de 5\%. Para a análise das fraturas foi realizada uma estatística descritiva. 


\section{Resultados}

Os valores das médias e desvio-padrão de resistência de união obtidos pelos CIV em função do tipo de substrato e da aplicação de ondas de ultrassom estão na Tabela 3. A aplicação de ondas de ultrassom influenciou positivamente os valores de resistência de união em todas as condiçoes experimentais estudadas, porém não houve interação entre as mesmas.

Tanto para o Ketac Molar Easymix quanto para o Vitremer, observou-se que a aplicação de ondas de ultrassom aumentou a resistência de união à dentina hígida $(p=0,001)$ assim como à afetada por cárie $(p=0,001)$.

$\mathrm{Na}$ mesma condição de dentina e material o uso do ultrassom resultou em maior resistência ao cisalhamento (Tabela 3).

$\mathrm{Na}$ análise das fraturas pôde-se observar que em todas as situações estudadas houve prevalência das fraturas mista e adesiva.

\section{Discussão}

No presente estudo foram utilizados dentes bovinos, uma vez que em teste de cisalhamento notou-se que não há diferença significativa entre a estrutura de dente humano e bovino (Miyazaki, et al., 1999). Muitos trabalhos utilizam dentes de boi (Miyazaki, et al.; 1999, Hara, et al., 2003; Souza-Zaroni, et al., 2006) em decorrência da facilidade de sua obtenção, manipulação (Hara, et al., 2003) e composição química relativamente uniforme, que permite menor variação em experimentos onde se faz necessário tratamento cariogênico (Mellberg, 1992). Além disso, o desenvolvimento de cárie em dentina bovina apresenta-se semelhante, em análise qualitativa, comparado à dentina humana (Mellberg, 1992; Hara, et al., 2003), com similariedades na profundidade da lesão, assim como na perda de conteúdo mineral (Hara, et al., 2003).

Como o tipo de substrato utilizado influencia na resistência de união (Palma-Dibb, et al., 2003), este estudo avaliou tanto a dentina hígida como a dentina afetada por cárie. A dentina cariada artificialmente foi removida até se encontrar tecido clinicamente passível de remineralização (Mount e Ngo, 2000; Peters e McLean, 2001), porém diferente tanto química como estruturalmente da dentina hígida (Czarnecka, et al., 2007), e semelhante com as condições 
clínicas restauradoras atuais (Palma-Dibb, et al., 2003; Czarnecka, et al., 2007). Os trabalhos que avaliaram a resistência de união por meio de ensaio de cisalhamento, em sua grande maioria utilizaram dentina hígida (Miyazaki, et al., 1999; Wang, et al., 2006; Souza-Zaroni, et al., 2006; El Askary, et al., 2008) ou naturalmente cariada (Palma-Dibb, et al., 2003; Czarnecka, et al., 2007). Como o desenvolvimento de lesões de cárie artificiais permite melhor padronização desse substrato (Choi, et al., 2006; Carvalho, et al., 2008) este método foi utilizado no presente estudo com a inoculação de Streptococcus mutans, resultando em uma superfície com textura, coloração (Carvalho, et al., 2008) e profundidade (Choi, et al., 2006) similar a encontrada clinicamente.

Os valores de resistência de união em dentina hígida obtidos neste estudo para CIV convencional e CIVMR foram de 2,55 $( \pm 0,84)$ e $3,89( \pm 1,01)$ MPa respectivamente (Tabela 3 ), semelhantes aos de estudos que têm demonstrado que a resistência ao cisalhamento dos CIV convencionais varia de 1 a 3 MPa (Berry e Powers, 1994; Burke e Lynch, 1994) e 4,3 MPa para os modificados por resina (Miyazaki, et al., 1999).

O Ketac Molar, utilizado neste estudo, tem sido empregado em associação com o ácido poliacrílico, o qual promove suave desmineralização da superficie dentária (Ruse e Smith, 1991) e permite a formação de tags que são mecanicamente fracos e pouco contribuem para a retenção do material (Czarnecka, et al., 2007). O Vitremer, também utilizado, consiste de partículas de vidro degradáveis, soluções de poliácidos e monomêros resinosos tais como - HEMA, que possuem a capacidade de melhorar a resistência de união deste material à dentina (Ruse e Smith, 1991; Tyas, et al., 1991), proporcionando maior afinidade entre a superfície dentinária e o material (Titley, et al., 1996). Apresenta um primer ácido capaz de modificar a smear layer (Marquezan, et al., 2009; Fagundes, et al., 2009), desmineralizar a dentina mais superficial (Abdala, 2000), abrir os túbulos dentinários (Fagundes, et al., 2009) e garantir contato mais íntimo entre CIVMR e a dentina. Consequentemente permite a infiltração de monômeros resinosos e a formação de uma camada similar à camada híbrida encontrada quando da utilização de sistemas adesivos (Fritz, et al., 1996; Abdala, 2000; Pereira, et al., 2000).

Dependendo da composição do CIV, o uso de ondas de ultrassom pode influenciar favoravelmente em propriedades mecânicas do material (Tanner, et 
al., 2006). Pôde-se observar, neste estudo, que quando foi realizada a aplicação de ondas de ultrassom sobre ambos os CIV maiores valores na resistência de união à dentina foram obtidos. A aplicação de ondas de ultrassom gera melhor compactação do material (Towler, et al., 2001), que pode ser notada na interface cimento/dentina, promovendo íntimo contato com o substrato dentinário, o que possibilita maior resistência adesiva (Fagundes, et al., 2006). Além disso o uso de ondas de ultrassom sobre os CIV tem a capacidade de acelerar a reação de presa do material (Towler, et al., 2001, Towler, et al., 2003); proporcionar melhores propriedades mecânicas, como o aumento na dureza superficial (Towler, et al., 2001); reduzir a porosidade do material (Towler, et al., 2003) e melhorar a organização das partículas de vidro dentro da matriz (Kleverlaan, et al., 2004). A mudança no comportamento do material pode ser notada imediatamente após sua exposição ao ultrassom sendo que os efeitos são mais expressivos nas primeiras 24 horas (Towler, et al., 2001). O ultrassom pode ser utilizado também na cimentação de peças protéticas, sendo que a vibração produzida por alguns segundos altera a viscosidade (Walmsley e Lumley, 1995) do material. Quando a vibração cessa o cimento volta a seu estado sólido permitindo a obtenção de uma linha de cimentação mais delgada (Walmsley e Lumley, 1995).

Apesar do bom resultado encontrado na dentina hígida (Fagundes, et al., 2006), não há relatos sobre a resistência de união dos CIV com aplicação de ondas ultrassom sobre a dentina afetada por cárie, sendo este o substrato mais encontrado em situações clínicas. Na dentina afetada por cárie a resistência adesiva é prejudicada (Czarnecka, et al., 2007), o que também pôde ser observado neste estudo. Como o mecanismo de adesão ocorre entre os grupos carboxilicos do ácido polialcenóico e o íon cálcio da hidroxiapatita (Yoshida, et al., 2000) esse resultado era esperado devido à perda mineral decorrente da desmineralização na dentina intertubular e o menor conteúdo de cálcio disponível na dentina afetada por cárie (Palma-Dibb, et al., 2003). Essa menor resistência de união observada também pode ser devido a presença de túbulos dentinários obliterados por cristais de hidroxiapatita provenientes da dentina peritubular (Yoshiyama, et al., 2002), impedindo dessa forma ligação micromecânica entre o CIV e a dentina (Czarnecka, et al., 2007). Assim, a aplicação de ondas de ultrassom sobre os CIV Ketac Molar e Vitremer exerceu 
efeito positivo sobre os valores de resistência de união mesmo na dentina afetada por cárie.

A melhor performace adesiva após a aplicação de ondas de ultrassom alcançada neste estudo, pode também estar relacionada com o aumento de temperatura (Kleverlaan, et al., 2004, Algera et al., 2005), pois durante a propagação desse tipo de onda parte da energia é dissipada em forma de calor (Laird e Walmsley, 1991). Além disso o ultrassom promove a cavitação acústica, que consiste na formação, crescimento e colapso de bolhas produzidas pelo intenso aquecimento local (Laird e Walmsley, 1991). No CIV o colapso das bolhas lança ondas dentro do líquido que se propagam em alta velocidade atingindo as partículas adjacentes. Este fenômeno gera colisão das ondas com as partículas em ângulo direto promovendo o derretimento das mesmas. Pode-se observar também a colisão tangenciando as partículas, quando ocorre sua quebra (Doktycz e Suslick, 1990). A diminuição do tamanho médio das partículas após aplicação de ondas de ultrassom (Towler, et al., 2003) indica a presença de colisão entre as mesmas, o que torna o material mais susceptível em promover melhor mistura do pó com o líquido, ocasionando maior contato entre os componentes (Towler, et al., 2001). Também permite maior rapidez na difusão dos íons, formação de ligações cruzadas de ácido polialcenóico com os íons cálcio da dentina (Twomey, et al., 2004, Fagundes, et al., 2006) e consequentemente melhor compactação final e maior densificação do sólido (Towler, et al., 2001).

A partir dos resultados obtidos neste estudo in vitro, pode-se concluir que a aplicação de ondas de ultrassom pode ser indicada quando se deseja aumentar a resistência de união do CIV à dentina. 


\section{Relevância Clínica}

Diante do aumento da utilização da técnica de remoção seletiva de tecido cariado torna-se importante a busca por alternativas que possam melhor a adesão dos cimento de ionômeros de vidro a dentina afetada por cárie. 


\section{Referências}

Abdalla Al. Morphological interface between hybrid ionomers and dentin with and without smear-layer removal. J Oral Rehabil 2000; 9:808-814.

Algera TJ, Kleverlaan CJ, Gee AJ, Prahl-Andersen B, Feilzer AJ. The influence of accelerating the setting rate by ultrasound or heat on the bond strength of glass ionomers used as orthodontic bracket cements. Eur J Orthod 2005; 27: 472-476.

Berry EA, Powers JM. Bond strength of adhesive composites to dental substrates. J Prosthodont 1994;3:126-129.

Burke FM, Lynch E. Glass polyalkenoate bond strength to dentine after chemomechanical caries removal J Dent 1994;22:283-291.

Carvalho FG, Fucio SBP, Sinhoreti MAC, Correr-Sobrinho L, Puppin-Rontani RM. Confocal laser scanning microscopic analysis of the depth of dentin carieslike lesions in primary and permanent teeth. Braz Dent J 2008;19:139-144.

Cattani-Lorente MA, Dupuis V, Payan J, Moya F, Meyer JM. Effect of water on the physical properties of resin-modified glass ionomer cements. Dent Mater 1999;15:71-78.

Choi K, Oshida Y, Platt JA, Cochran MA, Matis BA, Yi K. Microtensile Bond Strength of Glass lonomer Cements to Artificially Created Carious Dentin. Oper Dent 2006;31:590-597.

Czarnecka B, Deregowska-Nosowicz P, Limanowska-Shaw H, Nicholson JW. Shear bond strengths of glass-ionomer cements to sound and to prepared carious dentine. J Mater Sci: Mater Med. 2007;18:845-849. 
Delbem AC, Cury JA. Effect of application time of APF and NaF gels on microhardness and fluoride uptake of in vitro enamel caries. Am J Dent 2002;15:169-172.

Doktycz SJ, Suslick KS. Interparticle collisions driven by ultrasound. Science 1990; 247:1067-1069.

El-Askary FS, Nassif MS, Fawzy AS. Shear bond strength of glass-ionomer adhesive to dentin: effect of smear layer thickness and different dentin conditioners. J Adhes Dent 2008;10:471-479.

Fagundes TC, Barata TJ, Bresciani E, Cefaly DF, Carvalho CA, Navarro MFL. Influence of ultrasonic setting on tensile bond strength of glass-ionomer cements to dentin. J Adhes Dent 2006;8:401-407.

Fagundes TC, Toledano M, Navarro MFL, Osorio R. Resistance to degradation of resin-modified glass-ionomer cements dentine bonds. J Dent 2009;37:342347.

Fritz UB, Finger WJ, Uno S. Resin-modified glass ionomer cements: bonding to enamel and dentin. Dent Mater 1996;12:161-166.

Glasspoole EA, Erickson RL, Davidson CL. Effect of surface treatments on the bond strength of glass ionomers to enamel. Dent Mater 2002;18:454-462.

Hara AT, Queiroz CS, Paes Leme AF, Serra MC, Cury JA. Caries Progression and Inhibition in Human and Bovine Root Dentine in situ. Caries Res 2003;37:339-344.

Kerby RE, Knobloch L. Strength characteristics of glass-ionomer cements. Oper Dent 1992;17:170-174.

Kleverlaan CJ, Van Duinen RNB, Feilzer AJ. Mechanical properties of glass ionomer cements affected by curing methods. Dent Mater 2004;20:45-50. 
Laird WR, Walmsley AD. Ultrasound in dentistry. Part 1--Biophysical interactions. J Dent 1991;19:14-17.

Marquezan M, Fagundes TC, Toledano M, Navarro MFL, Osorio R. Differential bonds degradation of two resin-modified glassionomer cements in primary and permanent teeth. J Dent 2009;37:857-864.

McLean JW, Nicholson JW, Wilson AD. Proposed nomenclature for glassionomer dental cements and related materials. Quintessence Int 1994; 25 : 587-589.

Mellberg JR. Hard-tissue substrates for evaluation of cariogenic and anticariogenic activity in situ. J Dent Res 1992;71(special issue):913-919.

Miyazaki M, Iwasaki K, Onose H, Moore BK. Resin-modified glass-ionomers: effect of dentin primer application on the development of bond strength. Eur $J$ Oral Sci 1999;107:303-309.

Mount GJ, Ngo H Minimal intervention: A new concept for operative dentistry Quintessence Int 2000;31:527-533.

Naasan MA, Watson TF. Conventional glass ionomers as posterior restorations. A status report for the American Journal of Dentistry .Am J Dent 1998;11:36-45.

Ngo H, Mount GJ, Peters MRCB. A study of glass-ionomer cement and its interface with enamel and dentin using a low-temperature, high-resolution scanning electron microscopic technique. Quintessence Int 1997; 28:63-69.

Palma-Dibb RG, de Castro CG, Ramos RP, Chimello DT e Chinelatti MA. Bond strength of glass-ionomer cements to carious-affected dentin $\mathrm{J}$ Adhes Dent 2003; 5:57-62. 
Pereira PNR, Sano H, Ogata M, Zheng L, Nakajima M, Tagami J, Pashley DH. Effect of region and dentin perfusion on bond strengths of resin-modified glass ionomer cements. J Dent 2000;28:347-354.

Peters MC, McLean ME. Minimally invasive operative care. II. Contemporary techniques and materials: An overview. J Adhes Dent 2001;3:17-31.

Ruse ND, Smith DC. Adhesion to dentine-surface characterization. J Dent Res 1991; 69:1610-1613.

Sennou HE, Lebugle AA, Gregoire GL. X-ray photoelectron spectroscopy study of the dentin-glass ionomer cement interface. Dent Mater 1999;15:229-237.

Shimada Y, Kondo Y, Inokoshi S, Tagami J, Antonucci JM. Demineralizing effect of dental cements on human dentin. Quintessence Int 1999;30:267-273.

Souza-Zaroni WC, Nhani VT, Ciccone-Nogueira JC, Chinelatti MA, PalmaDibbc RG, Corona SAM. Shear Bond Strength of Glass-ionomer Cements to Air-abraded Dentin. J Adhes Dent 2006;8:233-237.

Swift Junior EJ, Pawlus MA, Vargas, MA. Shear bond strength of resin-modified glass ionomer restorative materials. Oper Dent 1995;20:138-143.

Tanner DA, Rushe N, Towler MR. Ultrasonically set glass polyalkenoate cements for orthodontic applications. J Mater Sci: Mater Med 2006;17:313-318.

Titley K, Smith DC, Chernecky R. SEM observations of the reactions of the components of a light-activated glass polyalkenoate (ionomer) cement on bovine dentine. J Dent 1996; 24:411.

Toledano M, Osorio E, Osorio R, Garcia-Godoy F. Microleakage of class V resin-modified glass ionomer and compomer restorations. J Prosth Dent 1999; $81: 610-615$. 
Towler MR, Bushby AJ, Billington RW, Hill RG. A preliminary comparison of the mechanical properties of chemically cured and ultrasonically cured glass ionomer cements, using nano-indentation techniques. Biomaterials 2001;22: 1401-1406.

Towler MR, Crowley CM, Hill RG. Investigation into the ultrasonic setting of glass ionomer cements. part I. postulated modalities. J Mater Sci Lett 2003; 22: 539-541.

Twomey E, Towler MR, Crowley CM, Doyle J, Hampshire S. Investigation into the ultrasonic setting of glass ionomer cements. Part II: Setting times and compressive strengths. J Mater Sci 2004; 39: 4631-4632.

Tyas, M. Cariostatic effect of glass ionomer cement: a five-year clinical study. Aust Dent J 1991;36:236-239.

Vermeersch G, Leloup G, Vreven J. Fluoride release from glass-ionomer cements, compomers and resin composites. J Oral Rehabil 2001;28:26-32.

Walls AWG. Glass polyalkfenoate (glass ionomer) cements: a review. J Dent 1986;14:231-246.

Walmsley AD, Lumley PJ. Applying composite luting agent ultrasonically: a successful alternative. J Am Dent Assoc 1995;126:1125-1129.

Wang L, Sakai VT, Kawai ES, Buzalaf MAR, Atta MT. Effect of adhesive systems associated with resin-modified glass ionomer cements. J Oral Rehabil 2006;33:110-116

Wilson AD, Kent BE. A new translucent cement for dentistry. The glass ionomer cement. Br Dent J 1972;15:133-135.

Wilson AD. Resin-modified glass ionomer cements. Int J Prosthodont 1990;3: 425-429. 
Yap AUJ, Teoh SH, Hastings GW, Lu CS. Comparative wear ranking of dental restorative materials utilizing different wear simulation modes. J Oral Rehabil $2001 ; 24: 574-580$.

Yelamanchili A, Darvell BW. Network competition in a resin-modified glassionomer cement. Dent Mater 2008;24:1065-1092.

Yoshida Y, Van Meerbeek B, Nakayama Y, Snauwaert J, Hellemans L, Lambrechts $\mathrm{P}$, et al. Evidence of chemical bonding at biomaterial-hard tissue interfaces. J Dent Res 2000;79:709-714.

Yoshiyama M, Tay FR, Doi J, Nishitani Y, Yamada T, Itou K, Carvalho RM, Nakajima M, Pashley DH. Bonding of self-etch and total-etch adhesives to carious dentin. J Dent Res 2002;81:556-560. 


\section{Tabelas}

Tabela 1: Material, classificação, composição (principais componentes) e modo de aplicação dos CIV utilizados.

\begin{tabular}{|c|c|c|c|}
\hline CIV & Classificação & Principais componentes & Modo de aplicação \\
\hline $\begin{array}{c}\text { Ketac Molar } \\
\text { Easymix }^{\mathrm{TM}} \\
\text { (3M ESPE, St. } \\
\text { Paul, MN, } \\
\text { EUA) }\end{array}$ & CIV Convencional & $\begin{array}{l}\text { Pó: fibra de vidro e ácido } \\
\text { poliacrílico } \\
\text { Líquido: água, ácido } \\
\text { polietileno policarbônico e } \\
\text { ácido tatárico }\end{array}$ & $\begin{array}{c}\text { Aplicar o líquido do } \\
\text { produto sobre estrutura } \\
\text { dentária por } 10 \text { s, lavar } \\
\text { com água e secar. } \\
\text { Inserir o material na } \\
\text { cavidade. }\end{array}$ \\
\hline $\begin{array}{c}\text { Vitremer }^{\mathrm{MR}} \\
\text { (3M ESPE, St. } \\
\text { Paul, MN, } \\
\text { EUA) }\end{array}$ & $\begin{array}{l}\text { CIV } \\
\text { Fotopolimerizável }\end{array}$ & $\begin{array}{l}\text { Primer: HEMA, álcool etílico, } \\
\text { copolímero de ácido acrílico e } \\
\text { itacônico } \\
\text { Pó: fibra de vidro } \\
\text { Líquido: copolímero do ácido } \\
\text { acrílico e itacônico, água, } \\
\text { HEMA }\end{array}$ & $\begin{array}{l}\text { Aplicar o primer por } \\
\text { 30s, secar com jato de } \\
\text { ar por } 15 \mathrm{~s}, \\
\text { fotopolimerizar por } 20 \mathrm{~s} \text {. } \\
\text { Inserir o material na } \\
\text { cavidade e } \\
\text { fotopolimerizar por } 40 \mathrm{~s} \text {. }\end{array}$ \\
\hline
\end{tabular}

Abreviaturas: HEMA: 2-hidroxi-etil-dimetacrilato. 
Tabela 2: Grupos experimentais divididos de acordo com o substrato e tratamento

\begin{tabular}{|c|c|c|c|c|}
\hline \multirow{2}{*}{ CIV } & \multirow[t]{2}{*}{ Substrato } & \multirow[t]{2}{*}{ № de dentes } & \multicolumn{2}{|c|}{$\begin{array}{c}\text { Grupo } \\
\text { (número de corpos de prova) }\end{array}$} \\
\hline & & & Sem ultrassom & Com ultrassom \\
\hline \multirow{2}{*}{ Ketac Molar } & Hígido & 10 & 10 & 10 \\
\hline & Cariado & 10 & 10 & 10 \\
\hline \multirow{2}{*}{ Vitremer } & Hígido & 10 & 10 & 10 \\
\hline & Cariado & 10 & 10 & 10 \\
\hline
\end{tabular}

Tabela 3: Valores das médias de resistência de união (MPa) e desvio padrão, para dentina hígida e afetada por cárie em função da aplicação de ondas de ultrassom.

\begin{tabular}{lllll}
\hline \multirow{2}{*}{ Material } & Tipo de Dentina & \multicolumn{2}{c}{ Uso de Ultrasom } & \multirow{2}{*}{ Valor de $\mathrm{p}$} \\
\cline { 4 - 5 } & & NÃO & SIM & \\
\hline \multirow{2}{*}{ Ketac Molar } & HÍGIDA & $2,55 \pm 0,84 \mathrm{~A}$ & $4,45 \pm 1,13 \mathrm{~B}$ & 0,001 \\
\cline { 2 - 4 } & CARIADA & $2,10 \pm 0,59 \mathrm{~A}$ & $3,38 \pm 0,66 \mathrm{~B}$ & 0,001 \\
\hline \multirow{2}{*}{ Vitremer } & HÍGIDA & $3,89 \pm 1,01 \mathrm{~A}$ & $5,80 \pm 0,96 \mathrm{~B}$ & 0,001 \\
\cline { 2 - 4 } & CARIADA & $2,55 \pm 0,62 \mathrm{~A}$ & $4,26 \pm 0,54 \mathrm{~B}$ & 0,001 \\
\hline
\end{tabular}

Letras maiúsculas (na horizontal) diferentes demonstram diferenças estatísticas significantes entre os grupos, em cada material e tipo de dentina, comparando apenas o uso de ultrassom. 

Rugosidade superficial de Cimentos de lonômero de Vidro submetidos a aplicação de ondas de ultrassom: Avaliação após diferentes períodos de maturação.

\section{Carmen Regina Coldebella}

Departamento de Clínica Infantil da Faculdade de Odontologia de Araraquara UNESP. Rua Humaitá, 1680, Centro, 14801-903 Araraquara, SP, Brasil.

\section{Angela Cristina Cilense Zuanon (Autor Correspente)}

Departamento de Clínica Infantil da Faculdade de Odontologia de Araraquara UNESP. Rua Humaitá, 1680, Centro, 14801-903 Araraquara, SP, Brasil. Telefone: +55-16-33016335. e-mail: aczuanon@foar.br

Autor correspondente:

Profa. Dra. Angela Cristina Cilense Zuanon

Departamento de Clínica Infantil

Faculdade de Odontologia de Araraquara - UNESP

R:Humaitá, 1680 - Centro. CEP: 14801-903, Araraquara-SP Tel: (16)3301-6335 E-mail:aczuanon@foar.br 


\section{Resumo}

A lenta reação de presa dos cimentos de ionômero de vidro (CIV) pode favorecer o desgaste precoce do material, observado por meio de algumas alterações físicas como o aumento de sua rugosidade superficial. Ondas de ultrassom têm sido utilizadas como uma alternativa para minimizar essa desvantagem e garantir maior velocidade na reação de presa. O objetivo deste trabalho foi determinar a influência da aplicação de ondas de ultrassom sobre CIV por meio da avaliação da rugosidade superficial após ensaio de escovação em diferentes períodos de maturação do material. Os CIV Ketac Molar Easymix e Vitremer foram inseridos em matriz confeccionada com dente bovino, totalizando 32 espécimes de cada material, sendo que metade recebeu sobre sua superfície a aplicação de ondas de ultrassom por 30 segundos, durante sua reação de presa inicial. Após 24 horas $(n=16)$ e 30 dias $(n=16)$, antes e após ensaio de escovação, os corpos de prova, com $(n=8)$ e sem $(n=8)$ a aplicação de ondas de ultrassom foram submetidos à leitura da rugosidade superficial. Para análise estatística foram utilizados os testes ANOVA e Tukey ( $p \leq 0,05)$. Pôde-se observar que com a aplicação de ondas de ultrassom os CIV apresentaram menor rugosidade superficial apenas quando avaliados após 24 horas de sua manipulação. Concluiu-se que a aplicação de ondas de ultrassom é eficiente em promover menor rugosidade superficial logo após a manipulação dos CIV e que este efeito não pode ser encontrado em períodos avançados de maturação do material.

Palavras-chave: Cimentos de ionômero de vidro; ultrassom; desgaste de restauração dentária; escovação dentária. 


\section{Introdução}

Os Cimentos de lonômero de Vidro (CIV) são materiais constituídos a partir de uma reação de presa do tipo ácido-base [1] quando o pó, composto de sílica $\left(\mathrm{SiO}_{2}\right)$, alumina $\left(\mathrm{Al}_{2} \mathrm{O}_{3}\right)$ e fluoreto de cálcio $\left(\mathrm{CaF}_{2}\right)$, é degradado pelo líquido composto por uma solução aquosa de co-polímero do ácido acrílico, resultando em um sal de hidrogel [2].

Em decorrência de sua lenta reação de presa, os CIV convencionais necessitam de proteção superficial, pois podem absorver água [3], o que leva a perda de translucidez e erosão de sua superfície [4]. Sofrem também desidratação [3] que gera trincas no material [4]. Assim, considerável redução em suas propriedades físicas pode ser observada [3, 5]. Além disso, o lento processo de maturação retarda o desenvolvimento de sua resistência final, o que os torna propensos ao desgaste e susceptíveis à fratura [1, 6, 7].

A sensibilidade à umidade, baixa resistência mecânica e ao desgaste fazem com que as restaurações de CIV apresentem menor durabilidade quando comparadas com outros materiais restauradores [8], limitado-as a áreas de baixos esforços mastigatórios [9-12]. Quando o CIV entra em contato com a umidade antes de completar sua reação de presa pode sofrer alterações em suas propriedades que serão observadas ao longo do tempo [12, 13].

$\mathrm{Na}$ tentativa de acelerar a reação de presa dos CIV, mudanças foram realizadas no material como a alteração no tamanho das partículas [14, 15], do peso molecular do polímero [14] e a adição de monômeros resinosos como o 
HEMA [9, 16]. Este último possibilitou o controle da reação de presa pela aplicação de luz visível, melhorando a sensibilidade à umidade e algumas propriedades físicas $[8,11,16]$.

A aplicação de ondas de ultrassom sobre os CIV também tem se mostrado uma boa alternativa para melhorar algumas de suas propriedades físicas. Essa técnica permite a aceleração da reação de presa do material [12, 17], tornando-o menos susceptível à umidade e melhorando suas propriedades iniciais [18]. Propriedades como resistência à compressão [19] e à degradação a água imediatamente após sua inserção encontram-se melhoradas, devido a possibilidade de maturação precoce do material. Ainda é capaz de promover a diminuição de porosidades [17], melhorar o escoamento [20] e adaptação do cimento na cavidade [17, 21], além de promover melhor adesão ao esmalte [22].

Porém, pouco se sabe sobre as características superficiais iniciais dos CIV causadas pelo desgaste após a aplicação de ondas de ultrassom. $\mathrm{O}$ objetivo deste trabalho foi avaliar a influência da aplicação de ondas de ultrassom nos estágios iniciais de reação de presa de dois CIV, por meio da rugosidade superficial após a escovação, em diferentes períodos de maturação do material. As hipóteses nulas testada são: (1) a aplicação de ondas de ultrassom não promove diferença na rugosidade superficial dos CIV, (2) não há diferença na rugosidade superficial dos CIV em diferentes estágios de maturação.

\section{Materiais e métodos}

Preparo dos espécimes 
Foram utilizados os CIV Ketac Molar Easymix -KM-(3M ESPE, St. Paul, MN, EUA) e Vitremer -VT-(3M ESPE, St. Paul, MN, EUA), manipulados de acordo com as instruções do fabricante. Os materiais foram inseridos, com auxílio de uma seringa do tipo Centrix (Centrix - Shelton, EUA), numa matriz bipartida de dente bovino com uma cavidade central de dimensões de $4 \mathrm{~mm}$ de diâmetro por $4 \mathrm{~mm}$ de altura. Os grupos foram divididos segundo o material, uso (US) ou não (C) de ondas ultrassom e tempo de armazenagem (Tabela 1). Após inserção na matriz, os materiais foram cobertos por uma tira de poliéster. Nos grupos sem ultrassom, foi depositado sobre o conjunto um peso de $100 \mathrm{~g}$ durante um minuto, para planificação e extravasamento do excesso de material. Nos grupos com ultrassom, sobre a tira de poliéster foram aplicadas ondas de ultrassom com a ponta ativa do aparelho deslizando sobre toda a superfície do cimento e da matriz por um período de 30 segundos. Com intuito de não interferir nas propriedades nem na reação de presa do material o aparelho de ultrassom foi utilizado sem irrigação. Em seguida, com um peso de $100 \mathrm{~g}$ foi realizada pressão por 1 minuto para correta acomodação do material. O equipamento de ultrassom utilizado foi o PROFI III BIOS (Dabi Atlante, Ribeirão Preto, SP, Brasil), com $80 \%$ de potência. A ponta utilizada foi a Perio Sub (Dabi Atlante, Ribeirão Preto, SP, Brasil).

Todos os corpos de prova foram armazenados em umidade relativa do ar de $100 \%$ a $37 \circ \mathrm{C}$. Após 24 horas metade dos espécimes foi submetida a avaliação de rugosidade superficial e ensaio de escovação. A outra metade ficou armazenada em água destilada a $37 \circ \mathrm{C}$ até completar 30 dias de sua manipulação para então ser avaliada. 
Ensaio da escovação e análise da rugosidade superficial.

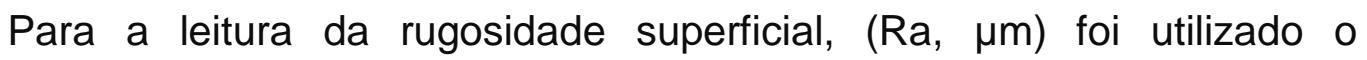
rugosímetro Surfcorder SE 1700 (Kosaka Corp, Tokyo, Japão). Foram realizadas nas superfícies de cada corpo de prova três leituras passando sempre pelo centro do mesmo. A média das três leituras resultou na rugosidade de cada superfície. Esse procedimento foi realizado antes e após o ensaio de escovação. Foi utilizado um cut off de 0,25 para maximizar a filtragem de ondulação superficial.

Para o ensaio de escovação os corpos de prova foram levados à máquina de escovação (Equilabor - Equipamentos para Laboratório Piracicaba - SP), que operou com velocidade constante de 250 ciclos (ida e volta) por minuto e pressão de $200 \mathrm{~g}$. Foram utilizadas escovas dentais de cerdas macias (Bitufo Class 32, Bitufo, Itupeva, SP - Barsil) e uma mistura de água destilada e dentifrício (Sorriso Dentes Brancos, Colgate Palmolive Ind e Com Ltda, SB Campo, São Paulo, Brasil) na proporção 1:1. Foram realizados 30.000 ciclos por corpo de prova e a cada troca de espécime também foram trocadas as escovas dentais e a mistura de dentifrício e água.

Após escovação, os corpos de prova foram lavados em água corrente e submetidos a banhos em cuba ultrassônica por 5 minutos, para então se realizar nova leitura da rugosidade, como descrito anteriormente. As leituras foram realizadas evitando a direção tomada pelos movimentos de escovação.

\section{Análise estatística}

A análise estatística foi realizada pelo teste t-student para avaliar a diferença de rugosidade antes e depois do ensaio de escovação e por meio do 
teste de Análise de Variância com três critérios fixos (material, maturação e ultrassom), com post hoc o teste de Tukey e a diferença estatística determinada por $p \leq 0,05$.

\section{Resultados}

Para todos os grupos estudados a rugosidade foi estatisticamente superior depois do ensaio de escovação (Tabela 2 ). Houve diferença estatística na interação para os dois períodos de avaliação e para os dois materiais empregados quando ondas de ultrassom foram aplicadas $(p=0,001)$. A Tabela 3 apresenta os valores da rugosidade após ensaio de escovação para todas as condições estudadas.

Os maiores valores de rugosidade puderam ser observados para o grupo VT C 24 horas, e os menores para o grupo VT C 30 dias. Pôde-se observar que os grupos com 24 horas de maturação apresentaram maior média de rugosidade quando comparados aos de 30 dias. Nesse último período de armazenagem não houve diferença entre os materiais estudados, assim como na a aplicação de ondas de ultrassom (Figura 1).

Após 24 horas de manipulação, pôde-se observar que as ondas de ultrassom influenciaram positivamente a rugosidade superficial dos CIV, promovendo valores de rugosidade estatisticamente inferiores em ambos materiais estudados (Figura 1). 


\section{Discussão}

A estética e longevidade clínica dos materiais restauradores dependem, entre outros fatores, de suas características superficiais [23, 24]. O aumento da rugosidade superficial do material restaurador leva ao acúmulo de biofilme, inflamação gengival, manchamento da restauração e cárie secundária [25].

A rugosidade superficial pode ocorrer em função do desgaste da restauração, o qual é resultado de sua baixa resistência à abrasão [26]. Baseados no fato de que a escovação dental é o procedimento mais comum e utilizado para a realização da higiene bucal e que esta prática leva ao desgaste tanto de restaurações como da estrutura dental [27], avaliou-se neste estudo a rugosidade superficial após ensaio de escovação.

Neste estudo pôde-se observar aumento da rugosidade superficial dos CIV após ensaio de escovação em todas as condições estudadas, fato também observado por outros autores [3, 23, 25, 27-29]. Variáveis como características da matriz, número e tamanho das partículas de vidro, exposição dessas partículas e formação de bolhas de ar durante a manipulação do material podem alterar sua rugosidade $[24,25]$.

Assim como outros autores [6, 29-32] pôde-se observar, após 24 horas, maiores valores de rugosidade superficial para o CIVMR quando comparado ao convencional, o que ocorre devido a resistência intrínseca dos principais componentes (matriz de polímero e partículas de vidro) de cada material, tamanho e forma das partículas de vidro e adesão entre essas e a matriz [30].

Observou-se que o uso de ondas de ultrassom promoveu diminuição na rugosidade superficial de ambos os CIV após 24 horas de sua manipulação 
(Figura 1). Ainda não foi estabelecido completamente o mecanismo de ação das ondas de ultrassom [13], mas sabe-se que seu efeito depende do tempo de aplicação [12], e que sua propagação pode ser notada a uma profundidade de $4 \mathrm{~mm}$ [18]. Acredita-se que as ondas de ultrassom têm a capacidade de quebrar as partículas de vidro assim como o aglomerado formado por elas [21]. Reduzindo o tamanho médio das partículas há melhora significativa nas propriedades mecânicas do material [33]. Prentice et al. [34] relataram que partículas de vidro menores em CIV proporcionam além de maior resistência à compressão, menor tempo de presa.

De acordo com a literatura [3, 13], o aumento na velocidade de reação de presa apresentado pelos CIV resulta em melhora das propriedades mecânicas iniciais, uma vez que atingem suficiente resistência às forças mastigatórias num período de tempo mais curto. Uma das maneiras de alcançar presa mais rápida é pela adição de uma fonte de energia externa, como de ondas de ultrassom [12, 17, 19, 21], que também proporciona aumento na dureza [17, 19] e compressão [19]; diminuição do tamanho e número de poros [21]; melhora no escoamento e adaptação do cimento [17, 20]; e de acordo com os resultados apresentados por este estudo, diminuição da rugosidade superficial causada pela escovação após 24 horas da manipulação do material. A aceleração no tempo de reação de presa para os CIV torna-os menos susceptíveis à absorção de água e promove 0 desenvolvimento de uma matriz mais uniforme [18]. Twomey et al. [35] relataram que, após um dia a resistência à compressão de CIV que receberam a aplicação de ultrassom foi equivalente àquela encontrada no material sem a aplicação das mesmas após 7 dias de armazenagem. 
Após 30 dias da manipulação, não houve diferença na rugosidade superficial dos materiais que receberam a aplicação de ultrassom (Figura 1), provavelmente devido ao seu alto grau de maturação, pois segundo Mount [36], embora a maturação do material leve alguns meses para se completar, depois de uma semana já encontra-se em estágio avançado. Kleverlaan et al. [19] também não encontraram diferenças quando avaliaram a resistência à compressão de CIV com e sem a aplicação de ondas ultrassom após período de armazenagem de 28 dias.

Atribui-se também à maturação do material a diferença para a rugosidade superficial encontrada ao comparar os cimentos avaliados em diferentes períodos de armazenagem. Após 24 horas de manipulação, ambos CIV apresentaram maiores valores de rugosidade superficial quando comparados com os de 30 dias de armazenagem. Ellakuria et al. [37] demonstraram aumento significante na dureza do Vitremer e Ketac Molar entre 1 e 15 dias de armazenamento, indicando também maior maturação do CIV com o passar do tempo.

\section{Conclusão}

A escovação foi capaz de promover aumento de rugosidade superficial para ambos os CIV, nos dois períodos de maturação aplicando-se ou não ondas de ultrassom.

A rugosidade superficial entre os materiais apresentou diferença apenas quando a avaliação ocorreu após 24 horas. 
A aplicação de ondas de ultrassom proporciona menores valores para a rugosidade superficial dos CIV avaliados após 24 horas de sua manipulação, melhorando essa característica do material. Porém com período de maturação de 30 dias a aplicação de ondas de ultrassom mostrou-se ineficiente. 
Referências

1 J.W. McLean, Br. Dent. J. 164, 293 (1988)

2 H. Yli-Urpo, P.K. Vallittu, T.O. Närhi, A.P. Forsback, M. Väkiparta, J. Biomater. Appl. 19, 5 (2004)

3 A.U.J. Yap, S.H. Teoh, G.W. Hastings, C.S. Lu, J. Oral Rehabil. 24, 574 (2001)

4 J.W. McLean, Oper. Dent. 17, 184 (1992)

5 G. Vermeersch, G. Leloup, J. Vreven, J. Oral Rehabil. 28, 26 (2001)

6 A.J. De Gee, R.N. van Dunien, A. Werner, C.L. Davidson, J. Dent. Res. 75, $1613(1996)$

7 J.D. Scholtanus, M.C. Huysmans, J. Dent. 35, 156 (2007)

8 K.M.Y. Hse, S.K. Leung, S.H.Y. Wei, Aust. Dent. J. 44,1 (1999)

9 C. Murdoch-Kinch, M.E. McLean, J. Am. Dent. Assoc. 134, 87 (2003)

10 D.A. Tanner, N. Rushe, M.R. Towler, J. Mater. Sci: Mater. Med. 17, 313 (2006)

11 R.N. Rafeek, J. Mater. Sci. Mater. Med. 19, 1913 (2008)

12 A. Talal, K.E. Tanner, R. Billington, G.J. Pearson, J. Mater. Sci: Mater. Med. 20,405 (2009)

13 C.L. Davidson, J. Appl. Oral Sci. 14, 3 (2006)

14 H.K. Yip, D. Peng, R.J. Smales, Oper. Dent. 26, 231 (2001)

15 R.N. van Duinen, C.J. Kleverlaan, A.J. de Gee, A. Werner, A.J. Feilzer, Dent. Mater. 21, 716 (2005)

16 S.K. Sidhu, Dent. Mater. 26, 7 (2010)

17 M.R. Towler, A.J. Bushby, R.W. Billington, R.G. Hill, Biomaterials. 22, 1401 $(2001)$ 
18 N.K. Thanjal, R.W. Billington, S. Shahid, J. Luo, R.G. Hill, G.J. Pearson, J. Mater. Sci: Mater. Med. 23, 589 (2010)

19 C.J. Kleverlaan, R.N.B. Van Duinen, A.J. Feilzer, Dent. Mater. 20, 45 (2004)

20 A.D.Walmsley AD, Lumley PJ, J. Am. Dent. Assoc. 126, 1125 (1995)

21 M.R. Towler, C.M. Crowley, R.G. Hill, J. Mater. Sci. Lett. 22, 539 (2003)

22 T.J. Algera, C.J. Kleverlaan, A.J. Gee, B. Prahl-Andersen, A.J. Feilzer, Eur.

J. Orthod. 27, 472 (2005)

23 S.K. Sidhu, M. Sheriff, T.F. Watson, Dent. Mater. 13, 208 (1997)

24 H.K. Yip, W.T.C. Lam, R.J. Smales, Br. Dent. J. 197, 265 (1999)

25 D. Rios, H.M. Honório, P.A. Araújo, M.A.A. Machado, Braz. Oral Res. 16, $343(2002)$

26 A.U. Yap, S.H. Teoh, G.W. Hastings, C.S. Lu, J. Oral Rehabil. 24, 574 (1997)

27 D. Slop, J.F. Rooij, et al, Caries Res. 17, 242 (1983)

28 S.B. Gladys, Van Meerbeek, et al, J. Dent. Res. 76, 883 (1997)

29 Y. Momoi, K. Hirosaki, A. Kohno, J.F. McCabe, Dent. Mater. 13, 82 (1997)

30 A. Peutzfeldt, F. García-Godoy, E. Asmussen, Am. J. Dent. 10, 15 (1997)

31 D. Xie, W.A. Brantley, B.M. Culbertson, G. Wang, Dent. Mater. 16, 129 (2000)

32 F.G. Carvalho, S.B.P. Fucio, A.B. Paula, G.M. Correr, M.A.C. Sinhoreti, R.M. Puppin-Rontani, J. Dent. Child. 75, 112 (2008)

33 R.G. Palma-Dibb, C.G. de Castro, R.P. Ramos, D.T. Chimello, M.A. Chinelatti, J. Adhes. Dent. 5, 57 (2003)

34 L.H. Prentice, Tyas, et al. Dent. Mater. 21, 505 (2005) 
35 E. Twomey, M.R. Towler, C.M. Crowley, J. Doyle, S. Hampshire, J. Mater.

Sci. 39, 4631 (2004)

36 G.J. Mount, Oper. Dent. 24, 115 (1999)

37 J. Ellakuria, R. Triana, N. Minguez, I. Soler, G. Ibaseta, J. Maza, F. GarciaGodoy, Dent. Mater. 19, 286 (2003) 
Tabelas

Tabela 1: Grupos experimentais divididos de acordo com material utilizado, uso de ondas de ultrassom e tempo de maturação.

\begin{tabular}{|c|c|c|}
\hline Material & Aplicação de ultrassom & Maturação \\
\hline \multirow{4}{*}{ Ketac Molar Easymix } & \multirow{2}{*}{ Com } & 24 horas $(n=8)$ \\
\hline & & 30 dias $(n=8)$ \\
\hline & \multirow{2}{*}{ Sem } & 24 horas $(n=8)$ \\
\hline & & 30 dias $(n=8)$ \\
\hline \multirow{4}{*}{ Vitrmer } & \multirow{2}{*}{ Com } & 24 horas $(n=8)$ \\
\hline & & 30 dias $(n=8)$ \\
\hline & \multirow{2}{*}{ Sem } & 24 horas $(n=8)$ \\
\hline & & 30 dias $(n=8)$ \\
\hline
\end{tabular}

Tabela 2: Médias e desvio padrão para a rugosidade superficial dos grupos experimentais, antes e depois do ensaio de escovação.

\begin{tabular}{|c|c|c|c|}
\hline \multirow{2}{*}{ GRUPOS } & \multicolumn{2}{|c|}{ SITUAÇÃO } & \multirow{2}{*}{ Valor de $p$} \\
\hline & ANTES & DEPOIS & \\
\hline VT-24H-CONTROLE & $0,3812 \pm 0,0321 \mathrm{~A}$ & $1,5010 \pm 0,1881 \mathrm{~B}$ & 0,001 \\
\hline VT-24H-ULTRASSOM & $0,3544 \pm 0,0393 \mathrm{~A}$ & $1,0312 \pm 0,1643 \mathrm{~B}$ & 0,001 \\
\hline VT-30DIAS-CONTROLE & $0,3401 \pm 0,0979 A$ & $0,6440 \pm 0,0952 \mathrm{~B}$ & 0,001 \\
\hline VT-30DIAS-ULTRASSOM & $0,3036 \pm 0,0708 \mathrm{~A}$ & $0,7676 \pm 0,1100 \mathrm{~B}$ & 0,012 \\
\hline KM-24H-CONTROLE & $0,3544 \pm 0,0393 \mathrm{~A}$ & $1,0312 \pm 0,1642 \mathrm{~B}$ & 0,001 \\
\hline KM-24H-ULTRASSOM & $0,3655 \pm 0,0434 \mathrm{~A}$ & $0,8739 \pm 0,1134 \mathrm{~B}$ & 0,001 \\
\hline KM-30DIAS-CONTROLE & $0,3110 \pm 0,0664 \mathrm{~A}$ & $0,7571 \pm 0,1064 \mathrm{~B}$ & 0,001 \\
\hline KM-30DIAS-ULTRASSOM & $0,3706 \pm 0,1333 \mathrm{~A}$ & $0,7591 \pm 0,1598 \mathrm{~B}$ & 0,002 \\
\hline
\end{tabular}

Abreviaturas: VT - Vitremer; KM - Ketac Molar Easymix. Letras maiúsculas (na horizontal) diferentes demonstram diferenças estatísticas significantes entre os grupos, pelo teste-T para amostras pareadas. 
Tabela 3: Valores da média e desvio-padrão para a rugosidade (Ra- $\mu \mathrm{m})$ dos materiais após ensaio de escovação, em diferentes períodos de maturação.

\begin{tabular}{c|c|c|c|c}
\hline \multirow{2}{*}{$\begin{array}{c}\text { Grupos } \\
\text { Experimentais }\end{array}$} & \multicolumn{2}{|c|}{24 horas } & \multicolumn{2}{c}{30 dias } \\
\cline { 2 - 5 } & 1,5010 & 0,18811 & 0,6440 & 0,09516 \\
\hline VT C & 1,0312 & 0,16426 & 0,7676 & 0,11046 \\
\hline VT US & 1,0312 & 0,16424 & 0,7571 & 0,10643 \\
\hline KM C & 0,8739 & 0,11337 & 0,7591 & 0,15977 \\
\hline KM US & & & & Desvio Padrão \\
\hline
\end{tabular}

C - controle; US - Com ultrasom. 


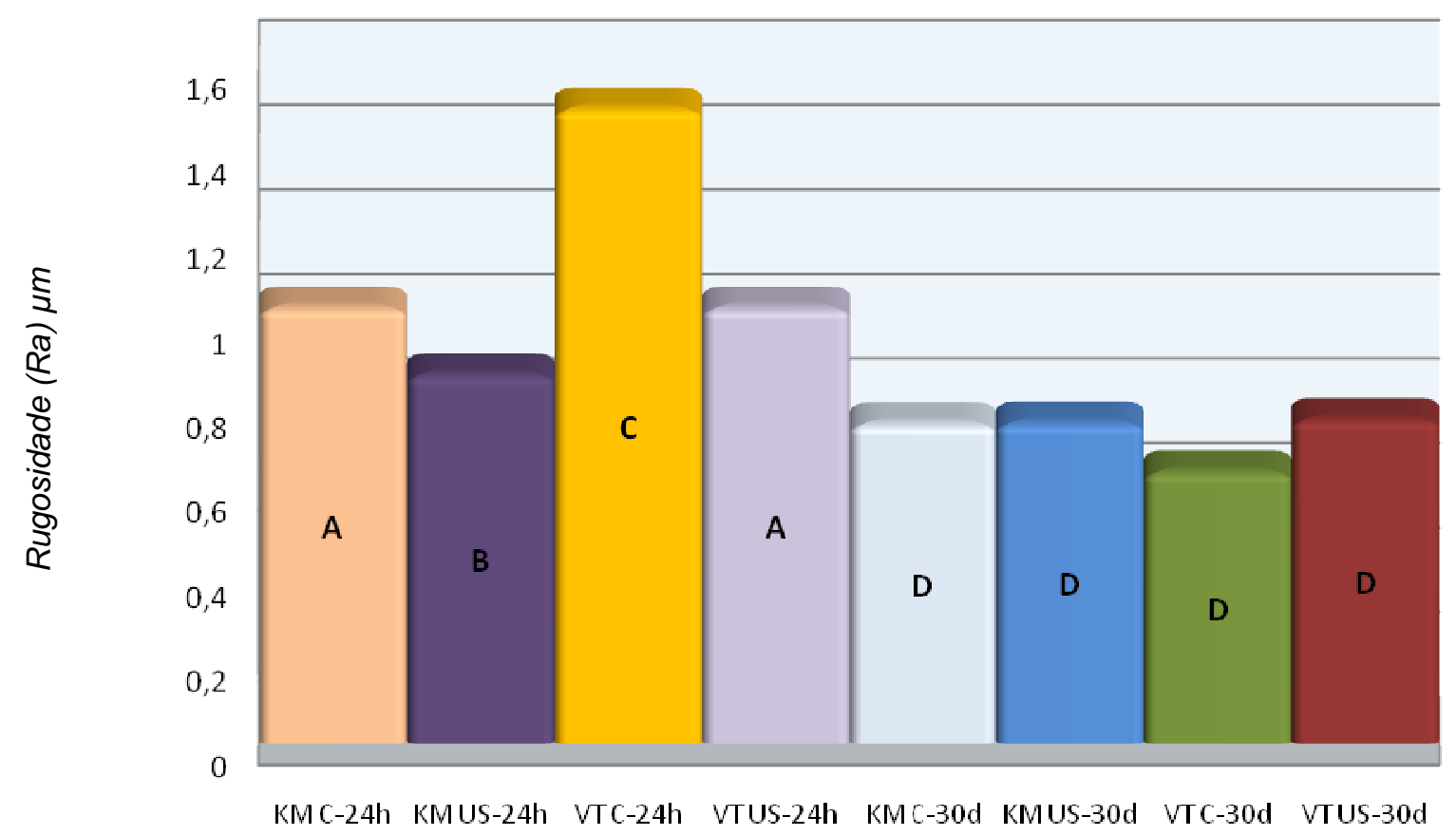

Grupos experimentais

Figura 1: Médias de rugosidade $(\mathrm{Ra}-\mu \mathrm{m})$ após ensaio de escovação, para todos os grupos experimentais em diferentes períodos de maturação. Letras diferentes caracterizam diferença estatística entre os grupos. 


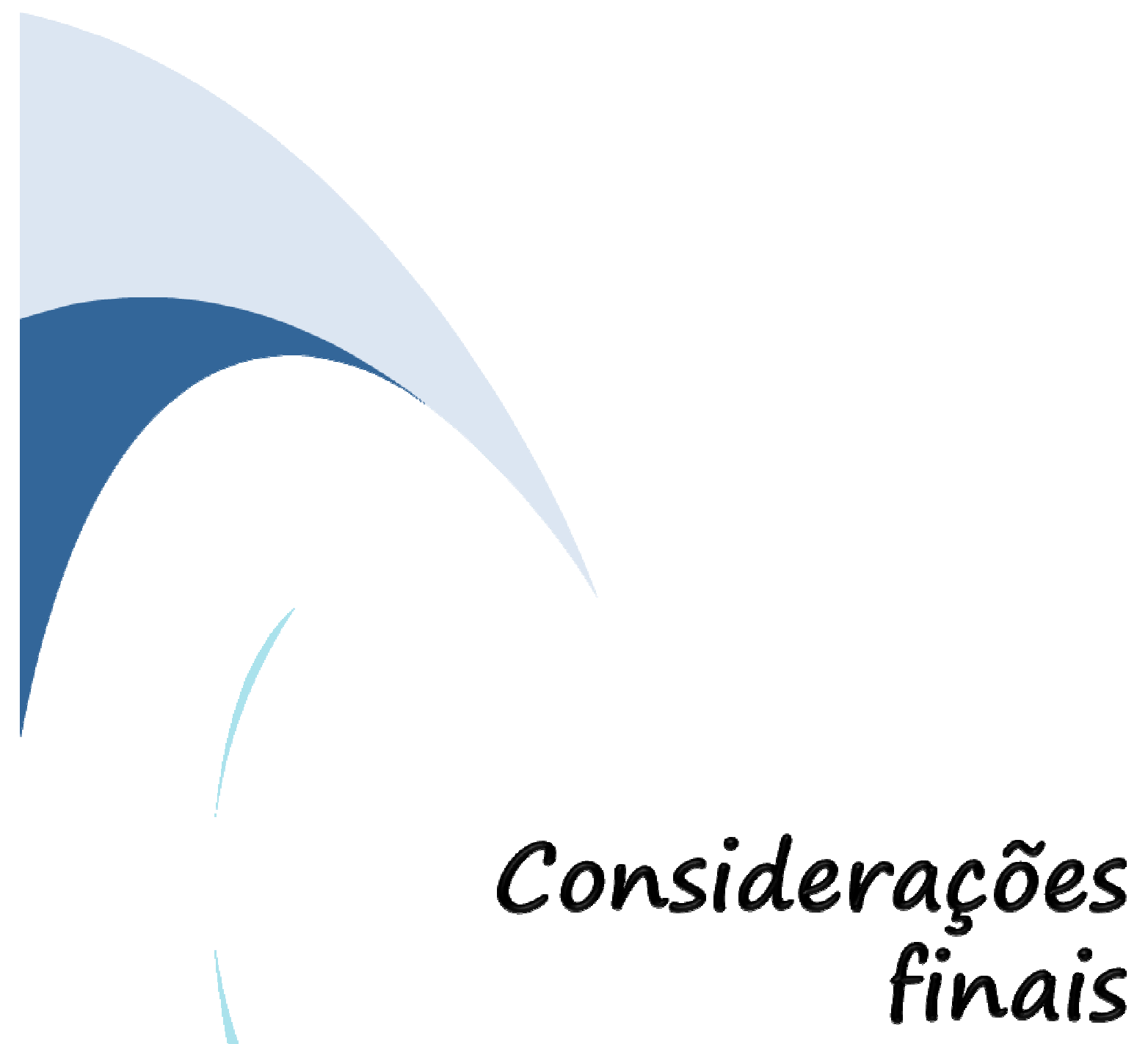




\section{CONSIDERAÇÕES FINAIS}

Os CIV são materiais com características peculiares que os tornam desejáveis para o uso clínico. Apresentam, porém, lenta reação de presa tornando-o propício a sofrer o fenômeno de sinérise e embebição. Consequentemente propriedades mecânicas como a resistência à compressão e ao desgaste podem ser alteradas, o que resulta em menor longevidade clínica da restauração. Desta forma, torna-se interessante o desenvolvimento de métodos capazes de acelerar sua reação de presa.

Uma alternativa é a utilização de ondas de ultrassom sobre o cimento de ionômero de vidro logo após sua inserção na cavidade. A técnica tem mostrado a capacidade de acelerar de forma significativa a reação de presa do material| $\left.\right|^{22,45,50-52}$ e melhorar suas propriedades mecânicas ${ }^{45}$. Possibilita também melhores valores de dureza superficial ${ }^{44,50-51}$, maior resistência à compressão ${ }^{22,52}$ e reduz porosidades internas do material ${ }^{51}$. Melhora ainda a capacidade de adesão ao esmalte ${ }^{1}$ e à dentina hígida ${ }^{11}$, a qual se difere da dentina cariada, apresentando maior conteúdo mineral ${ }^{54,62}$, o que pode influenciar na adesão.

Este estudo demostrou, após ensaio de cisalhamento, que tanto em dentina hígida como afetada por cárie, a aplicação de ultrassom por 30 segundos sobre dois CIV promoveu maiores valores de resistência à união. 
Apesar de não estar completamente esclarecido o mecanismo pelo qual as ondas de ultrassom agem ${ }^{8}$, acredita-se que seu efeito ocorra devido a melhor compactação do material $^{50}$, diminuição do tamanho médio das partículas ${ }^{51}$ que promove maior contato entre os componentes do material ${ }^{50} \mathrm{e}$ conseqüentemente, melhor mistura do pó com o líquido. Permite também difusão mais rápida dos íons e a aceleração da formação de ligações cruzadas do ácido polialcenóico com cálcio da dentina ${ }^{11,52}$, possibilitando melhor resistência adesiva ${ }^{11}$.

$\mathrm{Na}$ literatura pouco pôde-se encontrar sobre a dinâmica da liberação de flúor após a aplicação de ondas de ultrassom ${ }^{39,49}$. Sabe-se que com a aplicação da técnica os CIV podem liberar até $40 \%$ mais íons flúor ${ }^{39}$. Seu efeito cariostático é atribuído principalmente à sua habilidade de inibir a desmineralização e melhorar a remineralização48 por meio da liberação de íons flúor na estrutura dental adjacente ao material ${ }^{12,29,46,47}$.

A aplicação de ondas de ultrasom sobre os CIV interferiu positivamente na dureza dos dois tipos de dentina estudadas, sendo que a hígida apresentou maiores valores quando comparada à afetada por cárie, corroborando com outros estudos ${ }^{18,40,62}$. Pesquisas relatam que um dos mecanismos de ação das ondas de ultrassom sobre os CIV ocorre devido ao aumento de temperatura ${ }^{22,51}$.

O aumento da liberação de flúor porém não pode ser atribuído somente a esse fato ${ }^{49}$, uma vez que apenas a aplicação de calor prejudicou a liberação de flúor $^{58}$. Sabe-se que a atividade cavitacional provocada pelas ondas de ultrassom resulta na quebra das partículas de vidro e o aglomerado 
formado pelas mesmas ${ }^{51}$. Assim, aumenta a área de reação entre o pó e o líquido e possivelmente permite maior liberação e difusão de íons flúor.

Embora a literatura aponte várias vantagens após a aplicação de ondas de ultrassom sobre CIV, não há relatos quanto à sua contribuição em diminuir o desgaste à abrasão ocasionada pela escovação dentária sobre esse material.

Analisou-se também neste estudo a influência de ondas de ultrassom sobre o CIV com relação a sua rugosidade superficial após ensaio de escovação. Notou-se que a aplicação de ondas de ultrassom proporcionou menores valores na rugosidade superficial dos CIV quando avaliados após 24 horas de sua manipulação. Ao promover aumento na velocidade de reação de presa com a aplicação de ondas de ultrassom ${ }^{22,45,50-52}$ é possível que o material atinja suficiente resistência às forças mastigatórias num período de tempo mais curto. Porém quando avaliados após 30 dias de sua manipulação, não observou-se diferença estatisticamente significativa, provavelmente devido ao elevado grau de maturação atingido durante este período de tempo. Foi observado que após um dia de manipulação de CIV que receberam a aplicação de ultrassom, a resistência a compressão foi equivalente àquela encontrada em materias sem a aplicação de ondas de ultrassom após 7 dias de armazenagem ${ }^{52}$. Também não foram encontradas diferenças quando avaliada a resistência à compressão de CIV com e sem a aplicação de ondas ultrassom após período de armazenamento de 28 dias $^{22}$.

Em alguns CIV para cimentação a aplicação de ondas de ultrassom não foi capaz de melhorar suas propriedades mecânicas, concluindo que o efeito da técnica depende também do tipo de ionômero utilizado ${ }^{45}$. Neste 
estudo, independente do CIV utilizado, a aplicação de ondas de ultrassom promoveu melhora na rugosidade superficial, na resistência de união, assim como a dureza da dentina hígida e afetada por cárie subjacente ao material.

Assim, torna-se importante a investigação da aplicação de ondas de ultrassom sobre CIV em busca de melhores resultados clínicos e correta indicação da técnica, que demonstra ser uma alternativa bastante promissora. Foi capaz de melhorar adesão do material à dentina afetada por cárie, permitiu sua remineralização observada pelo aumento de dureza superficial e ainda apresentou a capacidade melhorar uma propriedade do próprio material, com a diminuição da rugosidade superfical. 



\section{Referências*}

1. Algera TJ, Kleverlaan CJ, Gee AJ, Prahl-Andersen B, Feilzer AJ. The influence of accelerating the setting rate by ultrasound or heat on the bond strength of glass ionomers used as orthodontic bracket cements. Eur J Orthod. 2005; 27: 472-6.

2. Braga RR, Meira JBC, Boaro LCC, Xavier TA. Adhesion to tooth structure: a critical review of "macro" test methods. Dent Mater. 2010; 26 : e38-e49.

3. Cattani-Lorente MA, Dupuis V, Payan J, Moya F, Meyer JM. Effect of water on the physical properties of resin-modified glass ionomer cements. Dent Mater. 1999; 15: 71-8.

4. Choi K, Oshida Y, Platt JA, Cochran MA, Matis BA, Yi K. Microtensile bond strength of glass ionomer cements to artificially created carious dentin. Oper Dent. 2006; 31: 590-7.

5. Christensen GJ. Compomers vc resin-reinforced glass ionomers. J Am Dent Assoc. 1997; 128: 479-80.

6. Crisp S, Wilson AD. Reactions in glass ionomer cements: III. The precipitation reaction. J Dent Res. 1974; 53: 1420-4. 
7. Czarnecka B, Deregowska-Nosowicz P, Limanowska-Shaw H, Nicholson JW. Shear bons strengths of glass-ionomer cements to sound and to prepared carious dentine. J Mater Sci Mater Med. 2007; 18: 845-9.

8. Davidson CL. Advances in glass-ionomer cements. J Appl Oral Sci. 2006; 14(Suppl): 3-9.

9. DeSchepper EJ, Thrasher MR, Thurmond BA. Antibacterial effects of glass ionomers. Am J Dent. 1989; 2: 51-6.

10. DeSchepper EJ, Berr EA, Cailleteau JG, Tate WH. A comparative study of fluoride release from glass-ionomer cements. Quintessence Int. 1991; 22: $215-9$.

11. Fagundes TC, Barata TJ, Bresciani E, Cefaly DF, Carvalho CA, Navarro MFL. Influence of ultrasonic setting on tensile bond strength of glassionomer cements to dentin. J Adhes Dent. 2006; 8: 401-7.

12. Forss $H$, Seppä L. Prevention of enamel demineralization adjacent to glass ionomer filling materials. Scand J Dent Res. 1990; 98: 173-8.

13. Frankenberger R, Sindel J, Krämer N. Viscous glass-ionomer cements: a new alternative to amalgam in the primary dentition? Quintessence Int. 1997; 28: 667-76. 
14. Fukuda R, Yoshida Y, Nakayama Y, Okazaki M, Inoue S, Sano H,et al. Bonding efficacy of polyalkenoic acids to hydroxyapatite, enamel and dentin. Biomaterials. 2003; 24: 1861-7.

15. Glasspoole EA, Erickson RL, Davidson CL. Effect of surface treatments on the bond strength of glass ionomers to enamel. Dent Mater. 2002; 18 : 454-62.

16. Hamilton IR. Biochemical effects of fluoride on oral bacteria. J Dent Res. 1990; 69 (Spec No): 660-7; discussion 682-3.

17. Hatton PV; Hurrell-Gillingham K; Brook IM. Biocompatibility of glassionomer bone cements. J Dent. 2006; 34: 598- 601.

18. Hosoya Y, Marshall SJ, Watanabe LG, Marshall GW. Microhardness of carious deciduous dentin. Oper Dent. 2000; 25: 81-9.

19. Hotz P, McLean JW, Sced I, Wilson AD. The bonding of glass ionomer cements to metal and tooth substrates. Br Dent J. 1977; 142: 41-7.

20. Hse KMY, Leung SK, Wei SHY. Resin-ionomer restorative materials for children: a review. Aust Dent J. 1999; 44: 1-11.

21. Kent BE, Lewis BG, Wilson AD. The properties of a glass ionomer cement. Br Dent J. 1973; 135: 322-6. 
22. Kleverlaan CJ, Van Duinen RNB, Feilzer AJ. Mechanical properties of glass ionomer cements affected by curing methods. Dent Mater. 2004; 20: $45-50$.

23. Laird WR, Walmsley AD. Ultrasound in dentistry. Part 1-Biophysical interactions. J Dent. 1991; 19: 14-7.

24. Liberman R, Eli I, Imber S, Shlezinger I. Glass ionomer cement restorations: the effects of lasing the cavity walls on marginal microleakage. Clin Prev Dent. 1990; 12: 5-8.

25. Lim HN, Kim SH, Yu B, Lee YK. Influence of HEMA content on the mechanical and bonding properties of experimental HEMA-added glass ionomer cements. J Appl Oral Sci. 2009; 17: 340-9.

26. Loyola-Rodriguez JP, Garcia-Godoy F, Lindquist R. Growth inhibition of glass ionomer cements on mutans streptococci. Pediatr Dent. 1994; 16 : 346-9.

27. McLean JW, Nicholson JW, Wilson AD. Proposed nomenclature for glassionomer dental cements and related materials. Quintessence Int. 1994;25: 587-9. 
28. Meiers JC, Miller GA. Antibacterial activity of dentin bonding systems, resin-modified glass ionomers, and polyacid-modified composite resins. Oper Dent. 1996; 21: 257-64.

29. Mitra SB. In vitro fluoride release from a light-cured glass-ionomer liner/base. J Dent Res. 1991; 70: 75-8.

30. Mjör IA. Glass-ionomer cement restorations and secondary caries: a preliminary report. Quintessence Int. 1996; 27: 171-4.

31. Mount, G. J. Glass ionomers: a review of their current status. Oper Dent. 1999; 24: 115-24.

32. Naasan MA, Watson TF. Conventional glass ionomers as posterior restorations. A status report for the American Journal of Dentistry. Am J Dent. 1998; 11: 36-45.

33. Ngo H, Mount GJ, Peters MC. A study of glass-ionomer cement and its interface with enamel and dentin using a low-temperature, high-resolution scanning electron microscopic technique. Quintessence Int. 1997; 28: 639.

34. Nicholson JW. Chemistry of glass-ionomer cements: a review. Biomaterials. 1998; 19: 485-94. 
35. Nicholson JW, Czarnecka B. The biocompatibility of resinmodified glassionomer cements for dentistry. Dent Mater. 2008; 24: 1702-8.

36. Pearson GJ, Atkinson AS. Long-term flexural strength of glass ionomer cements. Biomaterials. 1991; 12: 658-60.

37. Pereira LC, Nunes MC, Dibb RG, Powers JM, Roulet JF, Navarro MF. Mechanical properties and bond strength of glass-ionomer cements. $J$ Adhes Dent. 2002; 4: 73-80.

38. Rios D, Honorio HM, Araujo PA, Machado MAA. Wear and superficial roughness of glass ionomer cements used as sealants, after simulated toothbrushing. Pesqui Odontol Bras. 2002; 16: 343-8.

39. Rushe N, Towler MR. The influence of ultrasonic setting on fluoride release from glass polyalkenoate cements. J Mater Sci. 2006; 41: 5775-7.

40.Santiago BM, Ventin DA, Primo LG, Barcelos R. Microhardness of dentine underlying ART restorations in primary molars: an in vivo pilot study. Br Dent J. 2005; 199: 103-6.

41. Sennou HE, Lebugle AA, Gregoire GL. X-ray photoelectron spectroscopy study of the dentin-glass ionomer cement interface. Dent Mater. 1999; 15 : 229-37. 
42. Seppä L, Korhonen A, Nuutinen A. Inhibitory effect on S. mutans by fluoride-treated conventional and resin-reinforced glass ionomer cements. Eur J Oral Sci. 1995; 103: 182-5.

43. Swift EJ Jr, Pawlus MA, Vargas MA.Shear bond strengths of resinmodified glass-ionomer restorative materials. Oper Dent. 1995; 20: 13843.

44. Talal A, Tanner KE, Billington R, Pearson GJ. Effect of ultrasound on the setting characteristics of glass ionomer cement studied by Fourier Transform Infrared Spectroscopy. J Mater Sci Mater Med. 2009; 20: 40511.

45. Tanner DA, Rushe N, Towler MR. Ultrasonically set glass polyalkenoate cements for orthodontic applications. J Mater Sci Mater Med. 2006; 17: 313-8.

46. Tantbirojn D, Douglas WH, Versluis A. Inhibitive effect of a resin-modified glass ionomer cement on remote enamel artificial caries. Caries Res. 1997; 31: 275-80.

47. Tantbirojn D, Feigal RJ, Ko CC, Versluis A. Remineralized dentin lesions induced by glass ionomer demonstrate increased resistance to subsequent acid challenge. Quintessence Int. 2006; 37: 273-81. 
48.ten Cate JM, van Duinen RN. Hypermineralization of dentinal lesions adjacent to glass-ionomer cement restorations. J Dent Res. 1995; 74 1266- 71.

49. Thanjal N.K, Billington RW, Shahid S, Luo J, Hill RG, Pearson GJ. Kinetics of fluoride ion release from dental restorative glass ionomer cements: the influence of ultrasound, radiant heat and glass composition. J Mater Sci Mater Med. 2010; 21: 589-95.

50. Towler MR, Bushby AJ, Billington RW, Hill RG. A preliminary comparison of the mechanical properties of chemically cured and ultrasonically cured glass ionomer cements, using nano-indentation techniques. Biomaterials. 2001; 22: 401-6.

51. Towler MR, Crowley CM, Hill RG. Investigation into the ultrasonic setting of glass ionomer cements. part I. postulated modalities. J Mater Sci Lett. 2003; 22: 539-41.

52. Twomey E, Towler MR, Crowley CM, Doyle J, Hampshire S. Investigation into the ultrasonic setting of glass ionomer cements. Part II: Setting times and compressive strengths. J Mater Sci. 2004; 39: 4631-2.

53. Vermeersch G, Leloup G, Vreven J. Fluoride release from glass-ionomer cements, compomers and resin composites. J Oral Rehabil. 2001; 28: 2632. 
54. Wang Y, Spencer P, Walker MP. Chemical profile of adhesive/cariesaffected dentin interfaces using Raman microspectroscopy. J Biomed Mater Res. 2007; 81A: 279-86.

55. Weerheijm KL, Kreulen CM, de Soet JJ, Groen HJ, van Amerongen WE. Bacterial counts in carious dentine under restorations: 2-year in vivo effects. Caries Res. 1999; 33: 130-4.

56. Wiegand A, Buchalla W, Attin T: Review on fluoride-releasing restorative materials - Fluoride release and uptake characteristics, antibacterial activity and influence on caries formation. Dent Mater. 2007; 23: 343-62.

57. Wilson AD. Resin-modified glass ionomer cements. Int J Prosthodont. 1990; 3: 425-9.

58. Woolford MJ; Grieve AR. Release of fluoride from glass polyalkenoate (ionomer) cement subjacent to radiant heat. J Dent. 1995; 23: 233-7.

59. Yap AU, Pek YS, Cheang P. Physico-mechanical properties of a fast-set highly viscous GIC restorative. J Oral Rehabil. 2003; 30: 1-8.

60. Yap AU, Tan AC, Goh AT, Goh DC, Chin KC. Effect of surface treatment and cement maturation on the bond strength of resin-modified glass ionomers to dentin. Oper Dent. 2003; 28: 728-33. 
61. Yip HK, Peng D, Smales RJ. Effects of APF gel on the physical structure of compomers and glass ionomer cements. Oper Dent. 2001; 26: 231-8.

62.Zheng L, Hilton JF, Habelitz S, Marshall SJ, Marshall GW. Dentin caries activity status related to hardness and elasticity. Eur J Oral Sci. 2003; $111: 243-52$ 
Autorizo a reprodução deste trabalho

(Direitos de publicação reservado ao autor)

Araraquara, 07 de Maio de 2010.

CARMEN REGINA COLDEBELLA 